\title{
GROWING UP WITH BLACK HAIR IN THE GTA: THREE WOMEN SHARE THEIR STORIES
}

By

\begin{abstract}
Melissa Bagirakandi, BA, York University 2017
\end{abstract}
\author{
An MRP \\ Presented to Ryerson University
}

In partial fulfillment of the

Requirements for the degree of

Master of Arts

In the School of

Early Childhood School

Toronto, Ontario, 2019

C Melissa Bagirakandi, 2019 


\section{AUTHOR'S DECLARATION FOR ELECTRONIC SUBMISSION OF A MRP}

I hereby declare that I am the sole author of this MRP. This is a true copy of the MRP, including any required final revisions.

I authorize Ryerson University to lend this MRP to other institutions or individuals for the purpose of scholarly research

I further authorize Ryerson University to reproduce this MRP by photocopying or by other means, in total or in part, at the request of other institutions or individuals for the purpose of scholarly research.

I understand that my MRP may be made electronically available to the public. 


\title{
ABSTRACT \\ SHARE YOUR STORY GROWING UP WITH BLACK HAIR
}

\author{
Master of Arts, 2019 \\ Melissa Bagirakandi \\ School of Early Childhood Studies \\ Ryerson University
}

The literature demonstrates that Black hair affects the identity of Black women. However, there is little research on how Black hair affects the identity of Canadian Black girls. For the purpose of this study, Black hair will refer to coiled textured hair, often referred to as "kinky". The goal of the present study was to understand the effects of Black hair on the identity of Black girls between the ages of 5 and 12. Three Black women between the ages of 20 and 35 were asked to recall their experiences growing up in Canada with Black hair. Following a Black feminist approach, data was collected through story telling in an open-ended interview and four themes were identified : caring for Black hair, hair altering, the future of Black hair, and influences on Black hair styling. The women in the study have a hopeful vision for the future of Black hair.

Keywords: Black hair, identity, Canadian context, childhood 


\section{ACKNOWLEDGEMENTS}

I would first like to thank all the women for sharing their stories. This project would not have been possible without the Black women who generously gave their time to share their stories.

Second, I would like to thank my thesis supervisor Dr. Rachel Berman, Graduate Program Director of the School of Early Childhood Studies at Ryerson University. Your interest and support for my research interest has been an integral part in my success in this project. Thank you for giving me the confidence to begin this project, and for the countless hours you spent reading and editing this MRP. I am eternally grateful for your support this past year.

Third, I would also like to thank my second reader Dr. Karline Wilson-Mitchell, Program Director of the Midwifery Education Program at Ryerson University. Thank you for sharing your invaluable feedback and knowledge.

Fourth, I would like to thank my boyfriend and my best friends for their continuous encouragement and support throughout my past year as a graduate student.

Finally, I would like to thank my family for their constant support. Thank you for being understanding of my goals and for supporting me in my times of doubt and frustration. 


\section{DEDICATIONS}

This paper is dedicated to the following people:

To all the Black women in my life who have shown me that being Black is beautiful, notably, my mom and my best friend who were supportive and encouraging of my "natural hair journey".

To my late grandfather, who is not physically present to share this moment with me but who was a strong believer in my academic success.

To all the Black folk who are struggling with their relationship with their hair, or who struggle in understanding that Black hair is beautiful, I dedicate this paper to you. May you understand that your hair is acceptable, important and beautiful. 
Photographs of Natural Hair
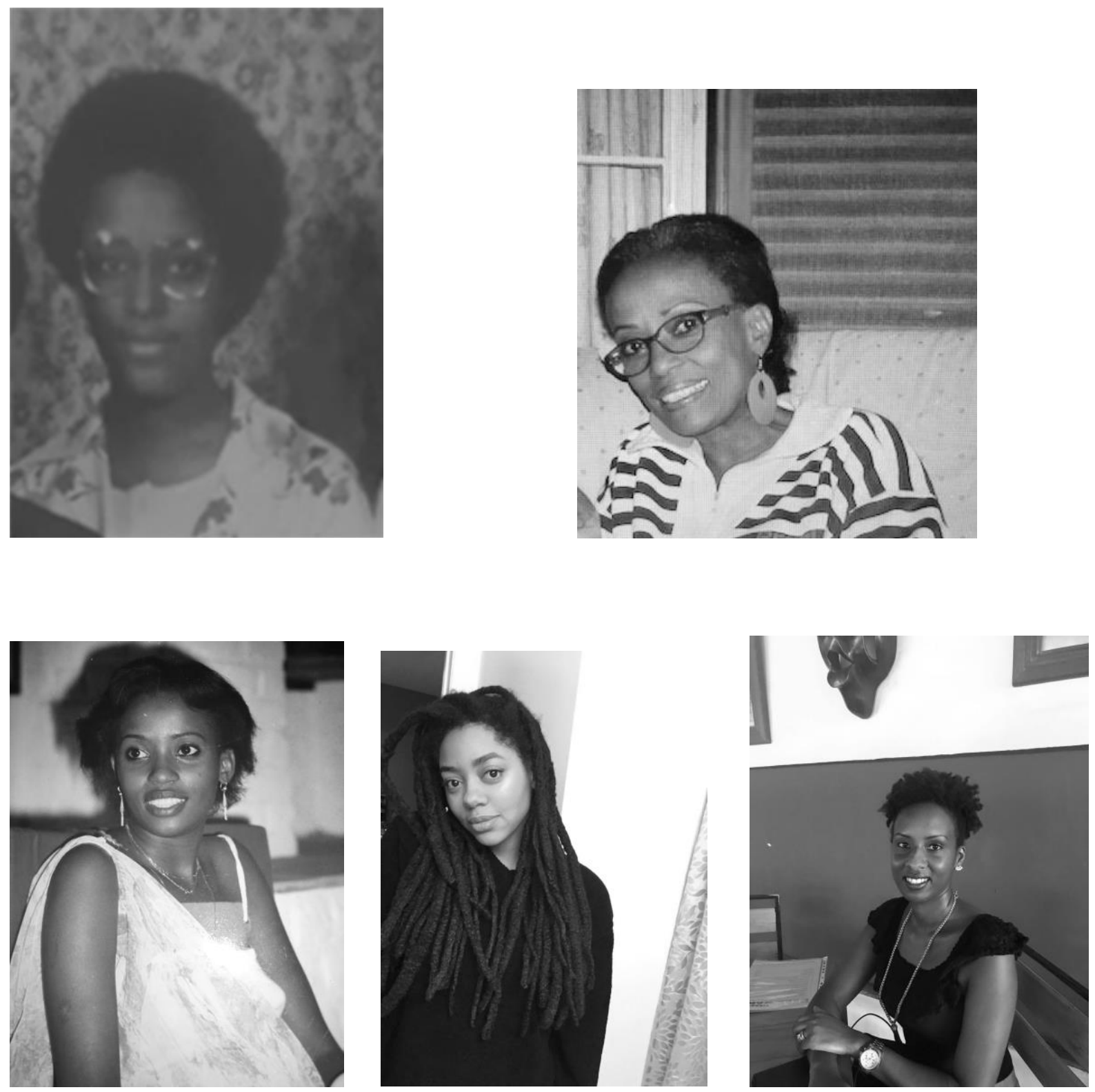


\section{TABLE OF CONTENTS}

Author's declaration

Page ii

Abstract .Page iii

Acknowledgements Page iv

Dedication Page v

Photographs of natural hair Page vi

Table of contents Page ix

List of Appendices Page iix

Chapter 1. Introduction. Page 1

Purpose Page 3

Research Question Page 5

Critical Paradigm Page 6

Theoretical Framework Page 6

Social Location Page 8

Chapter 2. Literature Review Page 9

What is Black Hair? .Page 9

The History of Black Hair .Page 10

The Role of White Supremacy on Black Hair Page 13

Black Hair Representation in the Media Page 14

The Consequences of Hair Altering .Page 15

Caring for Black Hair as a Caregiver .Page 16

Education and Black Hair Page 18

Black Girls, Hair and Identity ..Page 20 
Natural Hair Movement Page 21

Gaps in the Literature Page 22

Chapter 3. Methodology Page 22

Approach

Page 22

Ethical Considerations Page 23

Sample and Recruitment Page 23

Setting .Page 24

Data collection Page 25

Approach to data analysis

Page 27

Chapter 4. Findings Page 28

Caring for Black Hair

Page 29

Hair Altering .Page 31

The Future of Black Hair Page 34

The Influences on Black Hair Styling Page 37

Chapter 5. Discussion Page 41

Caring for Black Hair Page 41

Hair Altering .Page 43

The Future of Black Hair Page 45

The Influences on Black Hair Styling ............................... Page 46

Chapter 6. Strengths and Limitations Page 48

Trustworthiness Page 48

Credibility Page 49

Transferability .Page 49 


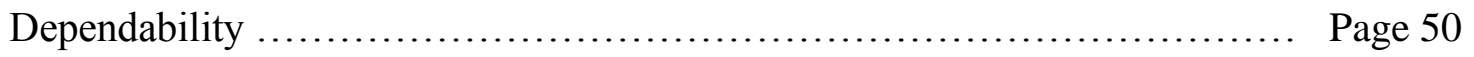

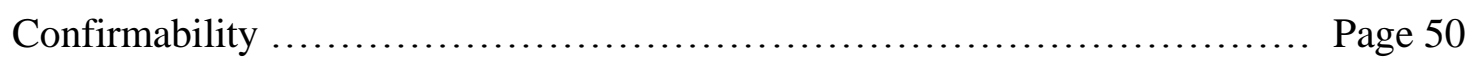

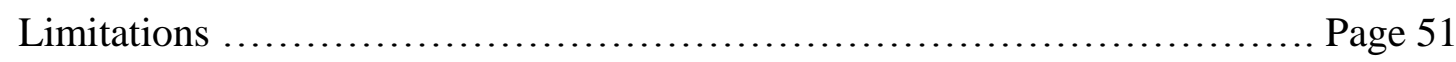

Chapter 7. Implications for ECE practice .................................... Page 52

Chapter 8. Future Study ....................................................... Page 53

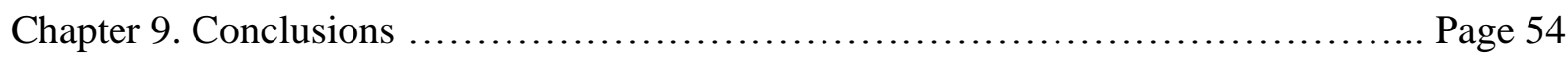

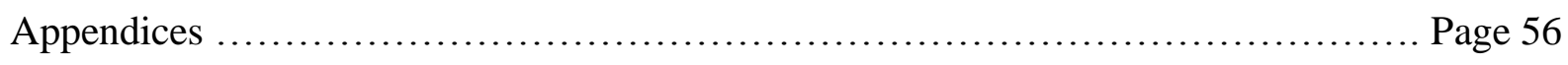

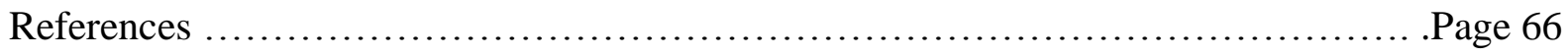




\section{LIST OF APPENDICES}

Appendix A: Recruitment Flyer

Page 56

Appendix B: In person Recruitment

Page 57

Appendix C: Informed Consent Form

Page 59

Appendix D: Demographic Questionnaire

Page 64

Appendix E: Approval letter from the Ryerson Ethics Board

Page 65 


\section{Chapter 1. Introduction}

It has been said that human hair is simply a natural and normal part of the body (Versey, 2014). However, hair has never been straightforward, or simply a biological fact, as it is almost always cared for or altered by human hands (Mercer, 1987). In fact, these practices can be seen to socialize hair in that Mercer (1987) describes hair as a raw material constantly influenced by cultural practices and beliefs. Thus, hair is evidently more than just a physiological part of the body, it holds a more meaningful significance. The significance and the importance of hair is especially meaningful to women and young girls as they are consistently told by society that being feminine is associated with hair, specifically long straight hair (Lester, 2000). However, research has demonstrated that the significance of hair is especially important to Black females. Aside from skin color, hair is the most tangible sign of racial difference (Mercer, 1987).

Therefore, hair for Black girls, is not just something to play with, it is related to their identity and self-esteem (Thompson, 2008). Most importantly, it affects how others perceive and treat them and as the literature demonstrates, Black women's hair is a part of their identity and it plays a role in how the world will perceive them and how they view themselves (Robinson, 2011; Rosette \& Dumas, 2007; Thompson, 2008).

Prior to Black Africans' forceful arrival in the New World, hair had a very strong spiritual meaning in Western Africa (Brisbon, 2009). Moreover, for Black African females, hair has and continues to be associated with cultural identity, spirituality, character makeup and the idea of beauty (Johnson \& Bankhead, 2013). However, throughout the era of slavery, slaves were forced to shave their hair, and consequently, a piece of their identity was gone. In an effort to gain back this piece of identity, Black females took advantage of products that were available to them such as bacon grease (Brisbon, 2009). Although these products were not always effective 
and safe, Brisbon (2009) further explains that hair was so important to the Black female population that they were willing to take hold of any opportunity to regain their agency and identity.

It eventually occurred to these women that in the New World, that the Western standard of beauty dominates (Yerima, 2017). According to this standard of beauty, beautiful hair is long and perfectly straight and there is a strong preference for non-kinky hair. Naturally, this belief creates a hair hierarchy, with long straight blond hair at the top and Black/African hair at the bottom (Thomas, 2013). The Western idea of beautiful hair strongly impacts and affects Black women (Robinson, 2011) as their hair is not naturally long and straight like many other women of different races (i.e.: white women). Moreover, these Western standards of beauty were not created for the Black women therefore it is even more difficult for them to attain (White, 2005). In fact, this standard of beauty is so powerful that it even created a caste system with the Black community, which perpetuates internalized racism and self-hatred. White (2005), explains that this caste system creates a hierarchy among Black populations, which suggests that those with more European features such as lighter skin and straighter hair have greater social value. This standard has significant consequences that affects the lives of many Black women on a social, economic and political level (Johnson \& Bankhead, 2014).

Essentially, the Western standard of beauty marginalizes Black females as they do not fit society's dominant image and idea of beauty. In addition, negative images and stereotypes of Black women have continuously been reinforced and serve to separate Black and White women from each other causing Black women to be invisible (Caldwell, 1991). Moreover, the discourse around race and beauty has historically been interrelated as racist ideologies have always promoted the appearance of the dominant group (Craig, 2006). Consequently, Black females 
continuously face racist intimidation, which begins as early as early childhood (Caldwell, 1991). In fact, studies on Canadian children and racial attitudes demonstrates that from a young age, white and racialized children tend to show favorable attitudes towards whites (Escayg, Berman \& Royer, 2017). Nevertheless, some Black women have historically made the decision to wear their hair in ways that do not reflect the Western standard of beautiful hair. Naturally this decision and form of assertion can sometimes enter in direct conflict with "the assumptions that underlie the existing social order" (Caldwell, 1991, p. 384). As Caldwell (1991) further explains, Black women who challenge dominant ideologies are viewed as "major threats to central national values" as they threaten the social, political and economic make-up of American life (p.392). Therefore, Black women who challenge the status quo by wearing their hair naturally or in braids, twists, dreadlocks and kinky, curly weaves are a threat to societal beliefs as they are reclaiming their identity and potentially empowering themselves.

\section{Purpose}

Practitioners, such as early childhood educators and teachers working with Black girls of African descent who wish to have a culturally responsive relationship with their students must understand the meaning of the individual's hair (Johnson \& Bankhead, 2014). As the literature demonstrates, Black hair has a strong and meaningful cultural history, which strongly impacts the identity of Black women and young girls.

Although beauty and hair advertisements are also directed towards men, the majority of these advertisements are strongly directed towards women. Moreover, Black women have historically been seen as inferior to Black men (Thomas, 2013). The literature even demonstrates that in comparison to Black men and White women, Black women experience a lack of overall sense of wellbeing and satisfaction and a sense of powerlessness (Scales-Trent, 1989). Therefore, 
research including the voices of Black women and girls must continue, as this is a way to empower a group that has historically been silenced, hence this study will focus on Black females.

From a developmental perspective, early childhood, specifically from ages 0 to 8 , is the most critical period for child development (UNESCO, n.d.). Various studies suggest that children develop an awareness of cultural and visible differences among and between people as young as two years of age (Aboud, 1988; Escayg, Berman \& Royer, 2017). However, as Perez (2017) explains, educators often do not feel comfortable discussing topics related to race and gender, and this can be quite detrimental for racialized children, as they are made invisible. In addition, when early childhood educators fail to have conversations surrounding race or when they chose to be 'color blind' they allow for racial incidents to become unnoticed and unreported. In fact, Berman et al., (2017) found that several participants in their study showed a tendency to minimize and negate racial incidents that may have occurred in their early childhood centers. The utilization of these practices have the potential to normalize racism and discrimination in early childhood settings. Thus, there needs to be more research on how hair plays a significant role in the development of identity to allow for the creation and implementation of new practices and frameworks in early childhood education. In turn, this would hopefully allow for a shift in the dominant discourse, which could only benefit the development of young Black girls.

As stated previously, a large portion of the research on Black hair and identity has been conducted in the United States which does not always simply transfer to a Canadian context. Although the United States and Canada have quite comparable and similar social and historical backgrounds, there are still differences in terms of discrimination and segregation experienced by the Black population between both countries (Fong, 1996). Canada simultaneously prides 
itself on its multiculturalism while denying their racist past. Although blatant anti-black racism is less common, the complexity of Black history along with the role and impact of racism is seldom discussed or questioned (Berman et al. 2017; Brown \& Brown, 2010). Canadians also have a different experience with Black hair care in comparison to Americans. As stated by Gordon, a beauty store owner, the small ethnic market in Canada (which supplies products for Black hair) does not receive the support and respect from manufactures, meaning that Canadians do not receive the same hair care supplies as Americans (Thompson, 2008). Therefore, as Canadian society is becoming increasingly diverse, it is crucial for the literature to include research that is specific to the experiences of Black women and young girls in a Canadian context. By only celebrating Canada's diversity and multiculturalism, the population is hiding from its anti-black racist practices and beliefs (Berman et al., 2017).

\section{Research question}

The present study will focus on the voices of Black females and their experiences growing up in Canada with Black hair. The study aims to answer the following: How did the experiences of Black Canadian women growing up with Black Hair impact their identity? More precisely, the participants will be asked to share their stories and experiences growing up with Black hair while focusing on ages 5 to 12 (for reasons which will be discussed later on in this MRP). I will utilize a Black feminist approach in the study when collecting and analyzing the data, as storytelling and the sharing of lived experiences is central to black feminist thought. Particularly, it allows for new facets, perspectives and narratives unique to those constructed by the dominant group to emerge (Perez, 2017). The goal is to begin to further understand how Black hair in the Canadian context shapes the identity of young Black girls. 


\section{Critical Paradigm}

There are multiple paradigms that can be utilized to guide social research (Leavy, 2017). The present study will be guided by a critical paradigm, which includes ideas from feminism, critical race. Research carried out within this paradigm has a focus on "social justice issues and aims to address the political, social and economic issues, which lead to social oppression, conflict, struggle and power structures and whatever level they might occur" (Kivunja \& Kuyini, 2017, p.35). As Leavy (2017) explains, a critical paradigm views research as "a political enterprise which has the ability to empower and emancipate" marginalized individuals (p.13). A critical paradigm is further guided by the ontological position of historical realism. As Scotland (2012) states, historical realism is the belief that our reality is shaped by several factors, notably, social, political, cultural, ethnic and gender values. Moreover, realities are socially contrasted and are under constant internal influence. Scotland (2012) further explains that the critical paradigm questions how things should be by critiquing reality. Creswell (2014), notes that specific issues that affect marginalized individuals, namely, inequalities, discrimination and alienation need to be addressed. These issues are often at the center of the research. In fact, the focal point of the present study is the voice and stories of Black women, a group that has continuously been marginalized and alienated by society. The study also aims to understand how these Black women's lives have potentially been affected by society and oppressors.

\section{Theoretical framework: Black Feminism}

In this study, a Black feminist approach will be used to both collect and analyze the data as storytelling and the sharing of lived experiences is central to black feminist thought. Black feminism allows for new facets, perspectives and narratives unique to those constructed by the dominant group to emerge (Perez, 2017). This theoretical framework further "demonstrates 
Black women's emerging power as agents of knowledge" (Collins, 1990, p.553) . As Perez (2017) states when Black women share their story, it also allows for a wider audience, beyond academic scholars, to have access to new ideas and perspectives that are not part of the dominant discourse. This is important as many Black women understand racism and sexism but cannot risk confronting and fighting for both forms of oppressions due to the constraints imposed by society (King \& Simmons, 2018). Collins (1990), a well known academic specializing in race and feminist theory, explains that Black feminist thought offers two significant contributions allowing us to further understand the connection between "knowledge, consciousness and the politics of empowerment.” (p.553). First, Black feminist thought creates a paradigmatic shift in how we view and think about oppression (Collins, 1990). Second, this worldview, as Collins (1990) explains, "addresses ongoing epistemological debates in feminism and in the sociology of knowledge concerning ways of assessing the truth." (p.553).

Black feminism is crucial in today's society in order to move away from traditional forms of feminism, which do not favor and benefit all women. Black women's critique of the history of feminism involves not only acknowledging the ways in which Black women have been excluded, but also the ways in which they have been made visible (Carby, 2007). Black women have essentially always been involved in the feminist movements but outside conservative forces, racism and elitism within the movements have affected their participation (Collective,1977). Consequently, Black feminists have been perceived as lacking feminist consciousness by other white feminist when in reality, Black feminist have always been committed to addressing interlocking oppression (Collins, 1986). The Collective (1977) further explains that their experiences and disillusionment within liberation movements led to the need to develop a movement or framework that was not only antisexist but antiracist. Racism and sexism are 
intersectional, they cannot be combated separately (Caldwell, 1991). Therefore, when considering gender inequalities, it is important to consider race, for example, the Western standards of beauty do not affect White females in the same ways they affects Black females.

\section{Social location}

I am a Black women who identifies as having Black hair, therefore my own experiences will affect the research and the interview process. Growing up in a predominantly white environment North of Toronto, Ontario I never thought my Black hair was good enough. I constantly chemically permed and straightened my hair to achieve straight hair, which I was conditioned to believe was much more beautiful and acceptable. I sacrificed several weekends as a child at the hair salon to maintain and treat my hair, a concept that was very difficult to explain to white children. Throughout the majority of my formal years, the saying "Beauty is pain" was very relevant to my relationship with my hair. I still remember the pain I felt while getting my coily hair brushed and the burns my scalp and neck endured from applying chemical relaxers to my hair. Nevertheless, this was my reality, I knew that every 3 months, I would need to chemically straighten my hair. In fact, until I was 22-23 years old I did not truly know how my natural hair looked like. Essentially, I spent the greater part of my life not truly knowing and understanding a part of my identity. Not only was I severely damaging my hair, I was denying a part of myself which strongly impacted my self-esteem. Attending post-secondary school in Toronto, a more diverse city, and befriending more Black women certainly gave me the confidence to embrace my Black culture. I began braiding and twisting my hair and even wearing it natural. This new change in my life did not come without consequences, I found myself needing to explain my hair styles to white women who rudely asked me "How did you get your hair like that?" and "Is this your real hair?" which were often followed by "Oh...that's 
nice". Although I love styling my hair in ways that reflect my Black culture, I dread answering these questions and facing judgement. I always wondered what would happen if I questioned a white woman on her hair.

Fortunately, I was privileged enough to attend post-secondary education and graduate school where I learned more about white supremacy, systemic racism and the intersections between race and gender. In graduate school I had the opportunity to further explore the work of Black academics, notably, bell hooks, Patricia Hill Collins and Audre Lorde. Their work and stories motivated me to further empower myself and other Black women and girls who are often excluded from the dominant discourse on feminism. Graduate school was also the first time I was exposed to Black feminism and critical race theory; these are theoretical frameworks which continue to guide my work and reinforce my beliefs in anti-racism. In this research study I want to give Black women a platform to share their experiences in a safe space. As stated, the larger goal is to begin to further understand how Black hair in the Canadian context shapes the identity of young Black girls. An additional goal is to give a voice to Black women and empower them as they share their important stories.

\section{Chapter 2. Literature Review}

\section{What is Black Hair?}

It is important to note that not all Black females have the same hair. In fact, there are several variations due to centuries of racial mixing and today, Black females can be seen with tight coiled hair, curly hair and even straight hair that has not been chemically treated (Robinson, 2011). The most common type of hair amongst Black females is described as "kinky". For the purpose of this study, Black hair will refer to the kinky, coiled textured hair. This type of hair affects texture and length as it soaks up moisture and is naturally quite dry; Robinson (2011) 
describes this phenomenon as the "Kink factor". The Kink Factor affects hair growth, meaning that achieving long hair to conform with dominant cultural ideas of beauty, is much more difficult for Black females with kinky hair (Robinson, 2011). This essentially demonstrates that Black "kinky hair" does not meet the European cultural standard of beauty.

As previously mentioned, most of the literature on Black hair has been done in an American context. Therefore, it is noteworthy to mention that most this literature review will also focus on research conducted in the United States, however, it is arguable still relevant in Canada because both countries do share similar histories with white supremacy and have access to the same mass media outlets.

\section{The History of Black hair}

Historically, there has been several shifts in how Black females style their hair. In 15 th century Africa, hairstyles demonstrated marital, status, age, class, ethnic identify and rank within a community (Thompson, 2008). It has also been used as a form of communication by several African groups (Johnson \& Bankhead, 2013). However, everything changed when slavery began. Slavers captured people from Africa and shaved their hair off, which was said to be for sanitary reasons (Bellinger, 2017). In fact, this was the first step in stripping Black Africans from their identity and lowering their status (Johnson \& Bankhead, 2013). Bellinger (2017) also explains that slave masters and mistresses typically told slave children to refer to their hair as wool and further encouraged them to dislike their own hair. This process clearly demonstrates the long history of the relationship between Black hair and white supremacy. Since Black Africans have arrived in the Americas they have been told that their hair is not valued and not presentable.

Throughout the era of slavery, slaves were separated based on their physical traits, specifically, Black women who were lighter in skin tone and had straighter hair worked in the 
home and those who had more African traits such as dark skin and coiled hair were forced to work in the fields (Robinson, 2011). Enslaved women then changed their hair depending on the labor they were required to do. Field slaves, who had less time to work on their hair, hid their hair as to not offend slavers (Thompson, 2008). In more severe cases, Byrd and Tharps explain that slave mistresses would force Black women to keep their hair unkempt and as a result, their hair and scalp were more susceptible to breakage, baldness and disease (as cited by Bellinger, 2017). On the other hand, house slaves wore their hair in the same way as their owners, typically with wigs (Thompson, 2008). As house slaves would spend an extensive amount of time with their slaves and their guests, Black women were encouraged to straighten their hair as to not offend any White people. (Bellinger, 2017).

The fact that slaves were separated based on their physical features illustrates the strong effects of colorism that still exist today. The divide created throughout this traumatic time in history, created distrust within the Black community which is still present today (Womack, 2016). Slaves who had features more like those of Europeans, notably, thinner hair and lighter skin were "good" while those of darker skin and coarser hair were "bad" (Robinson, 2011). This was one of the first times African beauty and hair were racialized (Johnson \& Bankhead, 2013). This belief has existed since the era of slavery and still exists today within the Black community. Bellinger (2017) explains that Black women were pressured to look as white/European as possible and even the slightest bit of kinkiness in one's hair was viewed as "bad" as they wouldn't be able to pass for white. Essentially, hair became the test of Blackness.

In the 1890's another shift occurred as Madam C.J. Walker and Anne Turbo Malone rose to prominence with the creation of the "hot comb", a device that was marketed to Black women to straighten their hair, however, once exposed to moisture, the hair reverted to its natural state 
(Johnson \& Bankhead, 2013; Thompson, 2008). As Johnson and Bankhead (2013) state, it is important to note that while Madam C.J. Walker didn't specifically invent the hot comb, she rendered the tool more accessible to Black women who desired straight hair. Nonetheless, this became controversial as Malone urged women of African descent to view themselves as African while at the same time offering a product that was meant to straighten their coiled textured hair (Johnson \& Bankhead, 2013). Regardless, several Black women continued to straighten their hair as they felt they had no choice if they were to be accepted by society.

In the 1960s the "relaxer", a hair and scalp chemical that keeps hair straight for 2-3 months, was introduced by George E. Johnson, which allowed for a more practical way to straighten hair at home (Thompson, 2008). Although the relaxer remains a commonly used product today, the 1960s and 1970s brought on a new political and radical movement for Black women with the emergence of the Civil Rights Movement and the Black Power Movement (Robinson, 2011). Black women began wearing their hair in braids and afros to display their hair's natural texture and demonstrate that Black is beautiful (Johnson \& Bankhead, 2013). The afro is a hairstyle that combines characteristics of curly, coiled and thick African hair which allowed Black individuals to shape and style their hair into numerous styles that would naturally hold (Dash, 2006). This political movement turned away from European aesthetics as they saw hair straightening as self-hate and self-denying (Iromuanya, 2018). Black individuals were returning and reclaiming their African roots and demanding societal change. It is important to note however that these political statements did not occur without any racist push back (Caldwell,1991).

Several years later, in the 1980's, the concept of weaves (synthetic or human hair sewn into the hair) became increasingly popular, which offered a variety of styles for Black women 
(Thompson, 2018). Today, several women are going back to wearing their natural hair, a concept that will be explored in this master's research paper (MRP). Several Black women are also silently going against the Western ideology of beauty by wearing curly weaves or twists (Thomas, 2013). The history of Black hair is evidently long and complex; however, it is crucial to understanding how it has and how it can shape the identity of Black women and young Black girls. Such an understanding can also allow for a shift in the normative discourse, particularly, how society views Black hair.

\section{The Role of White Supremacy on Black Hair}

Past research has demonstrated that Black women alter their hair to reject their natural "kinky" hair. More specifically, they reject their explicit Black features and imitate white characteristics, namely, straight long hair as a result of self-hate attributable to internalized white supremacy developed during the slavery era (Barnett, 2016; Thompson, 2008). Although African Americans managed to emerge from slavery with immense strength and resilience, they did not escape unscathed (DeGruy, 2005). Years of slavery certainly created years of abuse and trauma on a physical, psychological and spiritual level. This phenomenon is referred to as post traumatic slave syndrome. Similar to soldiers who experience post-traumatic stress disorder (PTSD), African American slaves also suffer from the trauma they experienced as a consequence of slavery. The effects of post traumatic slavery syndrome have been passed on through generations of parenting (Womack, 2016). This phenomenon led to internalized racism; the action of internalizing aspects of racism (Watts-Jones, 2002). Watts-Jones (2002) describes the process of internalized racism as "an experience of self-degradation and self-alienation; one that promotes the assumptive base of our inferiority" (p.592). 
Black women may also choose to alter their hair to conform with the dominant society's expectations in order to achieve high status and engage in what is perceived to be as professionalism (Rosette \& Dumas, 2007).This demonstrates the strong impact of white supremacy and internalized racism on Black women's hair which further perpetuates the idea that being White with long straight hair is the ideal. As previously mentioned, it is evident that Black hair does not conform with societal perceptions of beauty, therefore Black females often use their hair textures to create new hairstyles such as braids, weaves and dreadlocks (Robinson, 2011). Nevertheless, these diverse hairstyles, are still often perceived negatively as they conform with African origins rather than European ancestry (Robinson, 2011; Rosette \& Dumas,2007). Evidently, hair that resembles an African aesthetic and coiled texture is most often associated with a low status, which further supports the practice of white supremacy as it is linked to appearance. Furthermore, Oyedemi (2016) explains that a Eurocentric ideology of beauty has dominated African hairstyles, which threatens a potential social and cultural extinction of Black hair. This is an interesting point of view as it demonstrates the severity of and strong impact of white, European ideologies which still linger following the end of the slavery era.

\section{Black Hair Representation in the Media}

In contemporary society, the mass media is the main source for the transmission of racial, gender, sexual, and class ideologies and trends (Lindsey, 2013). Marginalized groups are not exempt from this bombardment of messages from the mass media, however, as Lindsey (2013) shares, the media can both reify and critique stereotypes of their respective groups.

Historically, African-Americans have been misrepresented and dehumanized in the media. In the $21_{\text {st }}$ century, popular culture still portrays straight long hair as ideal (Lindsey, 
2013). Black celebrities from Oprah to Beyoncé and even popular celebrities from children's television series such as Raven Symone and Keke Palmer are mainly portrayed with long straight hair (Lindsey, 2013). The representation of Black women with long straight hair paired with the consistent images of non-Black women with their long pin straight hair only further perpetuates the idea that the key to being beautiful and successful, is to have long straight hair.

Young black girls are not excluded from explicit messages regarding hair. Several advertisements targeted at young Black girls encourage and promote the use of "kiddie perms", chemical products that serve to temporary straighten kinky or curly hair (Lindsey, 2013). Commercials from products such as Just Like Me, a brand that offers "kiddie perms" depict the image of young Black girls with straight hair styles, once again perpetrating the idea that even amongst young Black girls, straight is ideal (Lindsey, 2013).

Although Black women and young girls are exposed to numerous misrepresentations of Black hair in the media, it is important to mention that several authors are working towards changing this phenomenon and creating a shift in the dominant discourse. For instance, a skit on Sesame Street entitled I love my Hair written by Jim Mazzarino challenges the Eurocentric belief that Black females should have their hair straight and long. The video illustrates a Black puppet with curly black hair expressing how much she loves her hair and everything it can be styled into such as twists and braids (Sesame Street, 2010). This is an ideal representation for young Black girls who may not see versions of themselves in the mass media on a regular basis. Additionally, it offers a new discourse for understanding the meaning of beauty (Lindsey, 2013). The recent Netflix original movie, Nappily Ever After illustrates Black women's struggle with maintaining the standard of European beauty by showing the process and restrictions they face in regard to their hair. For instance, Black women are told not get their hair wet when it is straight as this 
would revert the straight hair to its natural appearance (al-Mansour, 2018). The movie also depicts a young Black girl, whose father, a hairdresser, refuses to perm her hair. As the movie ends, all the Black characters with straight hair and wigs are seen jumping in a pool, which causes their hair to revert to their natural state, some women even remove their straight haired wigs. Indeed, this ending moves us away from the normative discourse and promotes the idea that Black hair doesn't always need to fixed or altered to match European standards of beauty.

\section{The Consequences of Hair Altering}

As mentioned in the previous section on white supremacy, Black women often alter their hair to conform to mainstream society's expectations and definition of beauty. In order to achieve the long straight hair that society deems most acceptable, Black women most often chemically relax their hair (Rosette \& Dumas, 2007). There are multiple types of chemical relaxers but all have the goal of temporarily straightening hair. These types of products contain various chemicals and are applied directly to the scalp for various periods of time, and are then rinsed off (Stiel et al., 2016). Dr. Dina Strachan, a New York City dermatologist explains that most of her African American patients complain about lack of hair growth, hair loss and breakage and this is due to hair alteration such as weaves and chemical relaxers (Thompson, 2008). These hair products can result in scalp lesions and burns (Stiel et al., 2016). The power of white supremacy is so entrenched that Black females are willing to physically hurt themselves to achieve this socially constructed idea of beauty (as discussed in the section on Social Location).

Another method Black women use to achieve straight is installing a weave. As previously noted, a weave is the process whereby synthetic or human hair is sewn into the hair (Thompson, 2008). There are several types of weaves that come in various lengths and qualities, therefore allowing one to achieve straight hair without using chemical products. In a similar fashion, 
women can also wear lace front wigs. Some Black women decide to glue the wig on their hairline to create the illusion of straight hair, however, they eventually cause a great deal of damage to the hair (Thompson, 2008). Black women can also use a flat iron, which is a tool that can straighten their hair and can be heated to 400 degrees (Johnson \& Bankhead, 2013). As previously mentioned, Black hair can be coarse and coiled in texture making it difficult to comb and style, therefore some women choose to straighten their hair, as this thins out the hair texture (Robinson, 2011). Naturally, excessive heating damages the hair overtime. The evidence clearly demonstrates that hair altering for Black women is a systemic issue that severely affects Black women on multiple levels.

\section{Caring for Black hair as a caregiver}

When considering a socio-cultural perspective, one can examine hair combing and how it relates to maternal touch. The process of combing Black hair requires repeated patting and touching of the child's hair, moreover, at times the child must sit on the mother or caregiver's lap or held between her knees (Lewis,1999). As Lewis (1999) further explains, the process of hair combing can either be harsh or nurturing. This practice therefore clearly illustrates a form of mother-child bonding and touch. Furthermore, the mother-child interaction that occurs during hair coming may bring forward implicit and overt messages and lessons on hair, identity and self-esteem. For the mother, hair combing may bring forth their own their early experiences with hair combing and for the child, this process allows for the positive development of their identity including their gender and race (Lewis, 1999).

Various factors influence the mother-child Black hair combing interactions and how this practice will later influence the child's identity. For instance, not all mothers are equipped to adequately care for Black hair as there are several skills to acquire, specifically, there are a 
variety styles and textures of Black hair and a certain amount of knowledge on Black hair (i.e.: braiding techniques, knowledge on chemical and thermal treatments) which will consequently affect the child's pride and self-esteem (Lewis, 1999). Based on the literature, it appears that hair combing and styling can also be a long, frustrating and possible painful process. For example, for biracial girls, whose hair care depends on a non-Black caregiver unfamiliar with Black hair, proper hair care can be quite challenging (Robinson, 2011). The same can be said for Black girls who are being raised by non-Black adoptive parents or other caregivers who may be unfamiliar with caring and styling Black hair. A perfect example is illustrated with the fictional family on the television show This is Us. The television show showcases a white mother (Rebecca Pearson) caring for her Black adoptive son's hair (Randall Pearson). In one the episode's a Black mother explains to Rebecca that her son Randall needs to get his hair cut by a professional who has experience with Black hair in order to avoid ringworms and hair bumps, which are causing him to scratch his head (Fogelman \& Todd, 2016). Naturally, it can be difficult for a caregiver to accept the fact they cannot care for all aspects of their child's identity. It is also important to note that even Black caregivers may be ill equipped to care for Black hair. Hair care can also become a very difficult and painful experience especially for Black girls. In fact, many Black women recall the experience of getting their hair combed, permed or straightened to be rather unpleasant or painful (Thomas, 2013). This is especially true for women or girls with a sensitive scalp, a problem often referred to as "tender-headed" in the Black community.

Nevertheless, it is important for Black hair to be properly cared for, as improper care can cause severe damage to hair, skin and even self-esteem. Similarly, a study by Ashley and Brown (2015) found that Black youth cannot care for or embrace their natural hair without guidance and support. It is not a surprise then that numerous Black young females perm their hair or get braids 
or weaves (Ashley \& Brown, 20015) as it is an easier way to "tame" their natural hair and look presentable in the eyes of the dominant group. Evidently, when looking at the connection between Black hair and identity, especially for young girls who do not yet style their own hair, the bond between child and caregiver is crucial.

\section{Education and Black hair}

In general, attending school as a Black child is challenging. Indeed, Canadian society is becoming increasingly diverse, however, the school system has not kept up with this change (Dei, 2003). There are several research studies conducted in education settings in a Canadian context, thus, this section will focus on the Canadian school system. Although many students succeed in Canadian educational systems, the truth still remains that power can be employed in racist ways to alienate or disengage Black and other racialized students (Dei, 2008). In general, history books in Canada have a tendency to marginalize Black history as they favor the stories and history of white heterosexual males (King \& Simmons, 2018). In fact, although Canada prides itself on its multiculturalism, "the origins and purpose of Canadian multiculturalism policy tend to be overlooked " as it is connected to the French and English as opposed to understanding Canada's diversity (Escayg, Berman \& Royer, 2017, p.12). Moreover, as King \& Simmons, (2018) further explain, when Black people are made visible in history textbooks, they are often depicted in a negative light or in ways that justify the racial inequalities they experience. Essentially, the textbooks fail to acknowledge Canada's past with racism when in fact white supremacy has always been present. Additionally, the literature indicates that lessons on Black history often take on an uncritical approach and fail to acknowledge or recognize white supremacy (King \& Simmons, 2018). Consequently, Canadian students and even educators may potentially view Canada as an accepting and tolerating environment with minimal racial 
injustice. Therefore, when Black students or other students of advocate for antiracism or share stories of racial inequalities, they may be silenced or viewed as perpetrating the "victim status" (King \& Simmons, 2018).

In Canadian schools, Black girls are at risk of facing discrimination and prejudice in school as their hair does not conform with the dominant ideology of beauty. In fact, their hair is simply not seen as clean and professional. In Western society, , most schools have a dress code of some sort but it would seem absurd for a school not to allow Black girls to wear their hair in its natural state. Interestingly enough, in 2019, California became the first state in the United States of America (USA) to ban hair discrimination. Although modern Western society has made strides towards racial equality, this new law clearly demonstrates the ignorance and prejudice that still exists today. In fact, a case which occurred in 2015 in the Toronto District School Board (TDSB), a school board in Toronto, Ontario, clearly demonstrates that Black girls can face harsh discrimination for simply wearing their natural hair to school. A school principal told a Black girl that her hair was "too poofy" and "unprofessional" and that she would not get hired with "hair like that" (Davidson, 2015). This case represents one example in which power alienates and disengages Black students, which further increases their chances of failure or "push out" (Dei, 2015) in the educational system. Forcing Black girls to wear their hair in straight styles is complex and detrimental to their overall wellbeing on several levels. As previously noted, constant hair straightening has numerous health consequences. Moreover, the cost of hair straightening (i.e. : visits to the hair salon to chemically straighten the hair) can become a financial burden, not to mention, Black hair care products are not always accessible to Black Canadian communities. In sum, by reinforcing these rules the dominant white group further reinforces systemic racial issues. 


\section{Black Girls, Hair and Identity}

As Thompson (2008) explains, hair for Black young girls, is not just something to play with, more specifically, it has the power to dictate how society will treat them and how they will perceive themselves. Through the effects of internalized racism, Black girls may view their hair as unequal to the dominant White race. Bellinger (2017) states that generally, the process of hairrelaxing begins at age six or eight. This would mean that, essentially, children may not even have the option of deciding if they want to alter their hair (King \& Niabaly, 2013). In many cases, young girls are essentially forced into the process of chemically altering their hair to constantly keep their hair straight. Naturally, this process damages the hair overtime, moreover, as Thompson (2008) states, these children do not even truly know how their natural hair looks like. In other words, a part of their identity is unknown. Once again, this further demonstrates the influence of white supremacy and societal expectations.

As explained in the above section, Canada's practice of multiculturalism tends to normalize Whiteness and consequently, non-White children, as such Black girls are viewed as the "other" (Escayg, Berman \& Royer, 2017). Therefore, as Escayg, Berman and Royer (2017) share, in comparison to other groups, white Canadian children psychologically benefit from whiteness and thus, have positive in-group attitudes. Yet, for a variety of reasons, for example, as a way to keep the child's presumed innocence, as a way to avoid supposedly complex and harsh topics, a lack of understanding, colorblind approaches, and so forth, educators often avoid the subject of race (Berman et al. 2017; Perez, 2007). Consequently, for Black children, a part of their identity essentially remains ignored. 


\section{Natural hair movement}

In the past few years, several Black females have shifted towards being part of a natural hair movement, free of hair straightening and chemical relaxers (Johnson \& Bankhead, 2013). The act of going back to one's natural hair is often referred to as "going natural" (Thomas, 2013). Natural hair is defined as hair with a kinky and coiled texture that has not been altered by chemical products (Bellinger, 2017). Janet Campbell, a hair salon owner in Toronto, Ontario has shared that in the past years she has seen more women going back to their natural hair as they test and experiment with their chemical-free locks (Thompson, 2008). In fact, several "Youtubers" are now showing their viewers how to style and care for their natural hair. Johnson and Bankhead (2013) explain that unlike the natural hair movement in the 1960's and 1970's, this new movement is not political. In this current movement, women are going natural, for the sake of their own hair ; they want to engage in a healthier lifestyle, explore their hair texture, save time and money and support their daughters' hair (Thomas, 2013). Yet, it would also be important to note that although it may not be their intent, going against societal beliefs is still political. In fact, "political hair is hair that challenges the traditional perception of beauty and hair that is acceptable in society" (Thomas, 2013, p.8).

Throughout the natural hair movement, more Black women are depicted in the media showcasing their natural hair. Nevertheless, caring for natural hair in Canadian society can be quite challenging. Black women must gain confidence to believe that their natural hair is beautiful and acceptable in society. Only once Black women believe that unaltered hair is acceptable will young girls also believe that their hair is beautiful and does not need to be changed. 


\section{Gaps in the literature}

This brief literature review provides a description of Black hair and its history. It highlights the importance and significance of hair for Black females. Although the topic of Black hair and identity has been explored, there are gaps in the literature as it pertains to the voices and experiences of young Black girls who are often excluded from this type of research. As mentioned in the literature review, most of the research on Black hair has been conducted in an American context. Even though the United States and Canada share similar historical contexts, there are several differences in terms of their policies. To the best of my knowledge, it appears that there are no studies in the literature that showcase how Black hair impacts the identity of Canadian Black girls.

\section{Chapter 3. Methodology}

\section{Approach}

For the purpose of this study, I employed a qualitative method to examine how Black hair has impacted the identity of Black females growing up in a Canadian society. Creswell (2014) describes qualitative research as "an approach for exploring and understanding the meaning individuals or groups ascribe to a social or human problem" (p. 32). One goal of qualitative research is to understand these interpretations in a specific point in time and in a particular context (Merriam, 2002). The present study explores the voices and experiences of three Black women growing up with Black hair in Canadian society. More, specifically, this study is theoretically informed by Black feminism. Indeed, this study will aim to understand three Black women's experiences with Black hair and how it has affected their identity, and form themes and patterns to build on existing hypotheses and theories. 


\section{Ethical Considerations}

Prior to conducting the study, I sought approval from Ryerson University’s Research Ethics Board (REB) by completing the online protocol application. Once my application was approved, I began recruitment. I recruited Black female participants who met the eligibility criteria of my study from my personal networks. These individuals also passed on information regarding my study to other Black females in their networks. My supervisor also recruited participants from her networks. All participants were recruited on a volunteer basis. They were also informed of the study they were taking part in and were provided with a clear understanding of what their participation entailed.

Throughout the entirety of the study, steps were taken to respect the confidentially of all participants. They had the opportunity to use pseudonyms to keep their identity as confidential as possible. All participants were also given the option to edit the transcriptions of their audiorecordings. The participants were also reminded that storytelling can cause the risk of feeling vulnerable or raise traumatic feelings or memories, however there was a debriefing period at the end of the interviews. During the data collection, specifically the participant's storytelling, I remained attentive of my relationships with the participants and ensured that their voices, as marginalized women, shone through. I ensured, to the best of my abilities, that the participants stories and experiences were guiding the research.

\section{Sample and Recruitment}

A purposeful sample was utilized for this study. This method allowed me to identify and collect information-rich cases in relation to the topic of Black hair and identity, the phenomenon of interest (Leavy, 2017). Snowball sampling as described previously was undertaken. More 
specifically, a poster flyer (Appendix A) and consent form (Appendix B) were given to my supervisor who distributed them through her network via email. I also asked Black women in my personal network to distribute flyers and recruitment letters to their networks. In every case, women who were interested in participating in the study contacted me via email. We then set up a time to meet and I booked a private study room at Ryerson accordingly. Two days before each interview, I emailed the participants an informed consent form to read through and ask questions. On the day of the interview, I provided the participants with a paper copy of the form which they then read and signed.

My 'insider-status,' as a Black woman, was an advantage when recruiting participants as I am associated with several Black communities in the Greater Toronto Area (GTA). In fact, 400,000 individuals identify as Black in the GTA, which may be why recruitment for this study was not foreseen to be a concern (Sienkiewicz, 2017). All potential participants with a previous relationship with myself or my supervisor, were reminded that their participation would be voluntary, and that this would not impact any future relationships with myself or with my supervisor, Dr. Rachel Berman and/or Ryerson University.

The sample consisted of 3 participants identifying as Black females with Black hair. The participants were aged 23, 26 and 30. All the women grew up in different areas of the GTA, specifically, Brampton, Toronto and Hamilton.

\section{Setting}

The study took place in downtown Toronto, Ontario, due the accessibility of the location and the availability of semi-private space. The interviews took place in library rooms at Ryerson University in Toronto, which I booked in advance for each interview. I made sure to book rooms 
in the graduate student section of the library as this floor is a silent floor, therefore there were little to no distractions during the interviews.

\section{Data Collection}

For the purpose of the study three Black women were asked to fill out a demographic questionnaire in order to be able to provide context for the data gathered and provide additional information, such as the specific Canadian province where they grew up as differences as this may be relevant. Following the demographic questionnaire, the participants were asked to recall their experiences with growing up with Black hair in Canada between the ages of 5 to 12. The participants were asked the following questions: "Can you recall and share your experiences growing up with Black hair in Canada?" They were also asked "Is there any particular experience regarding your hair that stands out for you?" The research then followed up with the questions: "Do you feel like your hair is of value or an equal plane with others?" and "Do you feel like you are able to care for your hair as well as most other people?" They were asked if they wanted to share anything else, and if they had any positive experiences with their Black hair.

The interviews were open-ended as I asked the participants these few specific questions and the rest of the interview continued like a conversation. Open-ended interviews can be challenging as the questions can develop into areas that were not anticipated (Hoffmann, 2007). However, this style of interviewing allows participants to contribute to the study with as much detail as they wish and it further gives space for the researcher to ask probing questions to continue the interview as a conversation (Turner, 2010). This experience was both helpful and challenging. The open-ended interviews I conducted were helpful and interesting as new ideas and perspectives I did not anticipate emerged. Yet, it was also challenging as I was required to give up control and at times, move away from the questions I was planning on asking the 
participants as these would not flow with the conversation. Specifically, throughout the interviews, it was sometimes difficult to focus on the participants' experiences with Black hair during their childhood (ages 5-12), as they often focused on adolescence and early adulthood.

Throughout the interviews, I made sure to be mindful of my position as a researcher and my 'insider' status. It was necessary to practice reflexivity throughout the entire research process. This challenged me to recognize and take responsibility of my position within the research and the potential affect it has on interview dynamics, the questions I asked during the interviews, and how I interpret the data (Berger, 2015). The practice of self-knowledge and selfreflection was crucial to the research as it helps recognize what aspects of the data stems from my own opinions, the participant or our interaction (Josselson, 2007). As Josselson (2007) further adds, reflexivity helps maintain an ethical relationship between the researcher and the research at hand. As a Black woman raised in Canada interviewing other Black woman also raised in Canada, it is likely that I share similarities with the participants. However, I cannot assume that we share the same lived experience with white supremacy and racism. Therefore, it was important for me to be mindful that my personal characteristics may influence my relationship with the participants, specifically, I recognized that this may affect the information participants were willing to share (Berger, 2015).

At the same time, my positionality also allows for insights regarding the topic and the analysis of the data that an "outsider" may not have. Throughout the interviews there were silent understandings that did not need interpretation (Johnson-Bailey et al., 2000). More specifically, there were times where the participants used terminology specific to Black hair, such as certain hair products and hairstyles that may not have been familiar to an "outsider". However, as 
Meriam et al., (2001) add, there are times were these understandings require asking for clarifications as our dialogue was not meant to remain completely private.

All interviews were recorded with a password protected device with the consent of the participants. They provided their consent on the informed consent form. Prior to starting the interview, I verbally asked the participants if I could record the interview. Once the audiorecordings were transcribed, they were immediately deleted. I decided to audio-record the interviews rather than taking notes as I would not be able simultaneously take detailed notes and listen to the participant during each interview. This could have also distracted the participant who may not continue speaking while I am note taking. Moreover, as Tessier (2012) notes, field notes may lead to bias and the researchers risk losing verbal and nonverbal data (as cited by Neal et al., 2015). Lastly, as one of the main points of the study is to hear the voices of Black females, by note taking, my full attention would not being given to these women, who have so often been marginalized and silenced.

\section{Approach to data analysis}

As data collected in a qualitative study can be quite dense and rich, not all information can be utilized (Creswell, 2014). Therefore, I opted to use a thematic analysis. Braun, Clarke, Hayfield and Terry (2018) explain that a thematic analysis allows researchers to "make sense of collective or shared meanings and experiences" (p.57). It is a way to identify important common themes in the data. This method was chosen due to its flexibility, specifically, it allowed me to view and focus on the data in several ways (Braun, et al. 2018). Moreover, this approach suits numerous research questions and topics.

To employ this method, I utilized Robson's (2011) approach to thematic coding. I first familiarized myself with the data by listening to the audio-recordings a few times to ensure that 
the participants verbatim was captured. Once all transcriptions were complete, I could start generating codes. I then moved on to the third step of Robson's (2011) approach as I began noticing similar themes emerging from the data. I then began coding the data by highlighting different sections and quotes from the transcriptions and associated them with different codes (Alsaawi, 2014). Once the data was coded, I started analyzing each code through the lens of my research question, paradigm and theoretical framework. At times, I re-read quotes or listened to specific parts of the audio-recording to ensure it was accurate. It is important to note that participants did have an opportunity to edit their transcription to ensure their stories were accurately conveyed and to respect their confidentiality. Once all the transcriptions were coded, I determined four themes that would best capture the participants stories.

The themes that I identified from the data are:

1. Caring for Black Hair

2. Hair altering

3. The future of Black hair

4. Influences on Black hair styling

\section{Chapter 4. Findings}

The findings of this MRP are reflective of the participants' stories, which they shared during their interviews. As mentioned above, four themes were identified during the data analysis. The themes are Caring for Black Hair, Hair Altering, The Future of Black hair and Influences. There were also subthemes identified. The next sections will present each theme and sub-themes. 


\section{Caring for Black Hair}

\section{Hair styled by mothers}

All women in this study recalled having their hair styled by their mothers at a young age. One participant shared that "my mother mostly would do my hair, she would you know put it in little plats, put little bubbles things like that...”.

Another participant also described how her mother would style her hair,

She would section it off and I guess detangle it and then twist it and then like just made sure it stayed twisted and then go to sleep when it's wet and wake up when it's still dry and then kind of do the same thing

A participant shared that her mother was the primary person who would care for her hair,

My mom was like the person who handled my hair when I was younger like you said 5 to 12 so I feel like from 5 to 10 that was when I didn't have a say in it and she was just like we have to do your hair. Most of the time she would braid my hair or you know put it into styles that she found easy or she liked. I remember all those pictures, like she was in charge of my hair. She would plan what she was gonna do and um yeah, my whole childhood I just remember my mom would do my hair.

\section{Painful experiences}

They further shared that the process of studying their hair was painful at times. A participant shared,

I remember just being bent over in the sink umm I would get soap in my eyes and then you know blow dry it or not even blow dry it but just trying to detangle it, that processing was definitely painful.

Another woman also described her hair care experience as a child and how styling her hair was dreadful, she explained "um a lot of stress about how long it would take, and it hurting and she would always threaten to like chop it all off".

\section{Hair salons}


The participants remember getting their hair styled at the hair salon for special events. One participant said, "And then if it was a special occasion or we were going on vacation, we would go to the hairdresser".

Two participants also express their satisfaction and memories with their hair salon and hair dressers. One participant even shared that she has not strayed from her hair dresser in several years,

Researcher: Yeah, so you're really attached to your hair salon?

Participant: Yeah! Yeah because she's just like I feel like she puts it to the pretty good texture and she doesn't usually burn me and yeah I just know what to expect

Researcher: Yeah, so to this day you still won't go anywhere else? Except to her?

Participant: So, the first salon I went to, where I got my hair permed was like my mom went to the salon and there were a few hairdressers there. She was one of the ones there, so I got different people to do my hair different times. But she was the best one, she branched off and made her own place in her basement, so I just kept on going to her.

Researcher: Ohh ok, yeah...

Participant: Soo since like grade 10 - grade 11 I've only been to her

Even when she moved away from home, she never strayed from her hair salon or hairdresser...

So, during undergrad I kind of got into the habit of only going when I would get back from vacation, so it would be like maximum every 4 months or something because it would just be when I come back, I didn't wanna find a new salon over there. I then actually after undergrad I moved to New York and I didn't find a new hairdresser there either, I just didn't want to, so I would go a pretty long time, I think the longest I did was like 8 or 9 months between hairdressers because I just don't want anyone else to do it

The other participant recalled her fond memories going to the hairdresser as a child,

But I do remember like...I remember the salon. Like going there with my brother umm were like 5 years apart but he still couldn't stay home by himself. So, we would come together he would have his Gameboy I would have coloring books or reading books, we 
would like walk around the corner, get a patty come back. Umm even though it was an all-day affair I kinda have fond memories of going to that hair salon.

She added,

I do...I think I have fond memories of that. Or like you go get candy at the corner store or something and I remember cause all the women in the salon were Jamaican, my family background though is bajan and so they would be talking but I wouldn't really know what they were saying (laugh) but it was very vibrant and lively um...yeah it was really like a whole day outing for sure

Researcher: Yeah... for sure

But I feel like my mom, you know we would bring things to do and get a snack and be like when she's done we can go um pick up dinner or something you know it was like a little family outing I guess

\section{Hair altering}

\section{Straightened hair}

The participants recalled when they first altered their hair, specifically by straightening their hair for special occasions or vacations. One participant specifically explained that "But when I got older like 10 or something, for weddings or graduations, my hair was always straightened for 6 graduation, grade 8 graduation...".

She also shared how important straight hair was to her and she specifically recalled being worried in situations which could cause her hair to revert to its natural state "Like I used to wear a hood, I used to wear a hood on top of a hood on top of an umbrella".

Throughout the interview with a participant the importance of straight hair became evident,

Yeah so after that I was like I'm just gonna have to straighten it myself. So, that was around middle school. I got my first hair straightener and I would blow dry, straighten, blow dry, straighten. Occasionally when like I couldn't for like gym activities or whatever I would just put it in a bun just to make sure that like...it was never out. If it wasn't straightened than it wasn't done, in my opinion like I thought it had to be straightened to look presentable and yeah so occasionally in middle school I wouldn't have it straightened just because life. Unfortunately, you can't always have it 
straightened, unfortunately it will change when the weather changes, or when you have to do sports so I just remember planning life around like "ok how's my hair gonna be like". I would literally think about "oh I can't be too active cause like we used to do the 12 minute run" or whatever...

\section{Reasoning for hair altering}

A participant explained that having her hair chemically permed would render hair styling easier.

She comparing having chemically straightened hair to straight hair styled by the pressing comb, and stated "But whenever I would have it done with the pressing comb, like it would be straight, it would be smooth it would be easier to manage."

Further, a woman explained how time is a factor,

But the thing is, not why I have to but why I chose to do it is more the time, like I can envision what I would do with my hair if it was natural but I'm just like it would take me so much longer than if I just had it relaxed, so I feel like I'd rather...

Another participant also shared that chemically perming her hair made her life a lot easier,

I mean, I didn't consciously choose to go natural at any point, it's just that in those big 6 months or whatever gaps between relaxing, you kind of have to treat it like its natural hair because there's so much growing so I just felt like it was really ruining my life to like devote all of Saturday or all of Sunday

Participants, shared that it was important for their hair to look "a certain way". More specifically, one woman explained "yeah it's all about looking a certain way obviously. Like I find it kind of hard to look as fancy without like straightening your hair". In a similar fashion, another woman explained that she felt she had to keep her hair straight,

And when I started to really like my hair like that, well I mean I liked it like that but in my mind, now, in retrospect, it was because of the compliments I got. I was like "oh my God my hair looks nice so I should keep it like this" 


\section{Consequences}

Although the women recall being happy with their straight hair, they are not ignorant to the consequences. They recognize the damage excessive heat and chemical products did to their hair over time. A participant recalled when she realized her hair was too damaged,

Participant: I was doing too much

Researcher: ...perming your hair?

Participant: Yeah with permed hair. So...I remember the second time I dyed it black, it was like the texture felt so different and I felt like I had damaged it

Another participant talked about her chemically relaxed hair and stated that,

I guess it depends on the climate or what I'm doing, but it's for sure more damaged than if it was natural. But I feel like I'm kind of getting into a groove like I use these natural shampoos and stuff and I'm trying to mitigate it. Umm and yeah it's for sure more damaged. But I feel like I'm generally ok with it.

In a subsequent interview one of the participants specifically described the state her hair was in from continuous straightening,

You can't stop the frizz, like I tried way too hard, like my edges, I was constantly brushing it down cause when my hair was straightened the back part was fine but when it starts to frizz it's like around here or at the top so that part was always so damaged, like even more damaged than the bottom part because obviously because it that was fine the next day I would be like "ok I'm not gonna re-do the whole thing I'm just gonna like straighten those hairs."

In another interview, a woman shared that the one time she did a "kid" relaxer and it had consequences on her hair,

So, we did a kid relaxer so obviously, it wasn't super strong but yeah it definitely changed the pattern of my hair and it wasn't the way I wanted it to be because I wanted it to be like fresh out of the salon. I was like "a box could do that!?" So, I was really disappointed when it didn't come out like that but it was different, my natural curl pattern was different my texture was different, just cause it's such a strong chemical right? 
Lastly, one woman explained how long it took to get rid of her damaged hair, she specifically stated "but it definitely took me like two and a half years to get rid of the heat damage but like a year before I could start wearing it curly and I was okay with how it looked."

\section{The future of Black hair}

\section{Hair care products and tools}

The availability and types of hair care products offered to Black women in Canada, specifically the GTA was discussed throughout the interviews. One of the women even said "And especially cause most Youtubers are American like when I was living in New York I definitely noticed that there were a lot more options".

We also discussed common hair products we used in the past and how we are only now realizing how inappropriate they were for Black hair. One participant specifically recalled,

When I look back on to things like Dax...I'm like no, I would not...we should not have been using that, it's like Vaseline in your hair

Researcher: Yes, I see...

It's like this thick green...thing ...um yeah, that's another thing looking back, it would be the types of products. I did a lot of learning about ingredients in products...so that would be something I would tell my younger self as well

Another participant added things would have been different for her growing up, had she had access to better hair products,

That's another thing, is if I grew up now I don't think I would have straightened my hair, if I grew up with all the hair products available, like accessible and you know the different hair types and obviously, there's more knowledge now like common knowledge now like people know there are different hair types and people know their natural texture and what products work for their type of hair

She then further described the lack of hair products accessible to her and her mother during her childhood, 
Participant: but I think their set up to do way better than I would of done. First of all the stuff that was available for my mom to do on my hair wasn't made for my hair and she would just use it cause it was there

Researcher: Yeahh

Participant: It is what it is. So now I feel like if she were to go into Shopper's she would be like oh this works way better for you and it would be like accessible, affordable price like it's there, she would have used that on me, so it's not lack of knowledge, its lack of availability. So, I feel like you're set up in that way like everything is more accessible to you, more representation where you can see how it would look, like I feel like now I don't think I would of gotten the comments that I got when I straightened my hair like as severe.

In another conversation, a participant stated,

Because back then, curly hair products or natural hair products like it wasn't a thing so the products that I used weren't made for my hair, they were made for straight hair so they wouldn't do anything so the moment when I would get out of the shower it wouldn't look curly it would look dry.

The types of tools offered on the market was also discussed, more specifically a participant stated,

Participant: Yeah and there's more gadgets. I've never used it but I've seen um silicon detanglers

Researcher: Oh, no I've never heard of that

Participant: Well I don't know if its silicon, but they fit in your hair and they have like little teeth, like very short teeth and somehow they better at detangling than a comb

Researcher: Ohh I think I've seen that, it's like a weird like size and it fits in your palm or something like that

Yeah I've been watching YouTubers rave about it, so I thought maybe if I have a kid with natural hair I would attempt to use more tools 


\section{Knowledge of Black hair and experience gained}

Throughout the interviews, the women explained that over the years, they have become more knowledgeable about their hair. One participant shared that she took the time to educate herself on her hair and which products are more suitable for her hair type,

Participant: And funny enough too when I started like on the journey of learning how to take care of it. I got a book called The Science of Black Hair

Researcher: Oh, wow

Participant: Um I think I just ordered it off Amazon and then I've actually shared that book with other friends who decided they wanted to go natural cause it really like there's a lot that you can learn that you don't realize that could like help you to build a regime and how to take care of your hair.

During the interviews, the women also shared that over the years, they have developed a routine on how to properly style and care for their hair. One woman specifically said, "I'm trying to balance out all the factors, and I feel like my least tangled experience is like twice a week umm only use like actually oil in my hair." Conversely, another woman shared that "So I feel like I had more time, since you know, that was the beginning of the whole natural hair on YouTube, I was researching more I was started to see like curly haired people like that I never saw before, like I wouldn't say mainstream, cause I don't think it hit mainstream yet”.

The participant also shared that over time she has grown to appreciate her hair and learn how to maintain it, she shared that "Like to me good hair is healthy hair. So, it's like I'm putting in the effort to figure out what works for me and taking care of it". She also noted that this process was helpful,

I feel like I just value what I have and being able to maintain it, and I'm also happy that I went through this process cause I feel like...

Researcher: Mhmm..

Once I have a daughter I will definitely be able to like help her...umm... more about her hair 


\section{Hair care}

The women who took part in the study can look back on their experiences with their Black hair and share what they would do differently. One participant even explained how she would care for her future daughters' hair,

With what I know now and going forward, I'd just give my daughter this information and this is how it can damage your hair doesn't mean it's more easy, you still need to take care of your hair so regardless of what style you're putting it in, just take care of it.

Along that same idea, a subsequent participant shared,

I mean it is what it is, I mean as stubborn as I was I don't think I could convince my daughter or my niece, like "you can't do this, you're banned, you don't even know what a straightener is!" but I would encourage them, like and you would be able to help them like "this would work for your hair, this would make your hair last, this would be a good style for you." And you could also try so many different things. Like my younger cousins or my cousins that have had kids they're doing amazing things with their hair. I love the styles that they do for pictures day or special occasions or little school concerts their hair is done naturally and it looks so nice in a way that my mom would not have been able to do just because number one she didn't know what worked best for my hair how it gets it to look like that. So, I just feel like it'll be better hopefully.

Another participant shared,

Um...but yeah I would say looking back I wish I could tell my mom to put some conditioner in my hair. I feel like I probably like I probably would have ended up perming it at some point just because...you just wanna like experience that and see how it is. Like I can understand that I feel like...for...with what I know now and going forward, I just give my daughter this information and this is how it can damage your hair doesn't mean it's more easy, you still need to take care of your hair so regardless of what style you're putting it in, just take care of it

In another interview, a participant explained how she would introduce Black hair care to her

future children, specifically, she shared,

I don't think I would relax their hair as a kid, I think I would do the same, like wait till they're in high school when they make up their mind. Umm yeah and I also feel like, don't know, I want them to know what it's like to take care of their own hair. 
Later in the interview. the same participant also said,

If I had kids, they should at least have a baseline of knowing what to do with their hair and not to be afraid of their own hair and deal with it and later on "if you want to relax it you can do it"

The Black women also explained that they are more equipped to style their hair due to previous experiences and research. Specifically, a participant compared her way of styling her hair to her mother's,

Umm...I feel like she was impatient to be honest, like now that I do my own hair, if I find a knot or something, I'm so gentle and I'll sit there as long as it takes to like untangle this hair. And my mom was kind of like "I have to do my hair and I have to do your hair" and like...

\section{Influences on Black Hair Styling}

\section{Mother's opinions and input in hair care}

As mentioned above, participants discussed how their mothers would style their hair growing up. They also discussed how their mothers shared their opinions and strong inputs in regard to their hair. All participants expressed that they wanted to chemically relax their hair to achieve straight hair. The first participant shared that "she wouldn't let me, I wanted to get a perm but she wouldn't let me until I went to high school" and followed by explaining her mother's reasoning as "Um she just said basically that I wasn't old enough yet...um and that she wanted me to wait and make sure that I was sure.” Another participant also shared a similar experience, she said "Umm we like talked about it on and off I wanted to do it again since I was little, like after the wedding but she's like it's not good for kids. She's like you shouldn't keep doing it and she was kind of like just wait." Finally, the last participant also stated "So, I was like I want a relaxer, I want a relaxer and she shut it down right away. She was like 'no you're gonna ruin your hair,' 
she's like 'don't do it.' I didn't listen to her I kept bothering her and then eventually she was like 'do what you wanna do'”.

The participants were also influenced by the way their mothers styled their own hair,

So, in that respect, like there wasn't anyone that I could look up to that had their natural hair and was used to rocking their natural hair. Um my mom also has 3 sisters um a few of them live in Barbados though but my mom's oldest sister um I grew up kind of thinking of her as a second mom she would always get like I guess a jerry curl so I never like...

One of the participant also mentioned that "No it was definitely influenced by her because she was very, she's gotten less that way now but she's very like glamorous about her hair". A participant further explained that she suspects a generational gap between herself and her mother,

Participant: Funny enough, now, cause even I was going natural, there were times when I would just wear my hair out, and she would be like...you didn't do your hair.

Researcher: Ohh ok

Participant: And I'm like no, this is just my natural texture

Researcher: Yeahh...

And without product, this is my hair. So, I feel like, there's also a bit of a generational gap. Cause it's the same with my aunt, like there's times when I would wear my hair in a certain style and she'd be like..".your hair looks unkempt, like what are you doing to your hair" (laugh). I'm like "no this is okay, like I'm fine with it, if you're not that's okay"

Researcher: Mhmm

But it's not like it would umm ...like...it didn't have a negative impact on our relationship. It was just more, I recognized that they're coming a different perspective that I think is also like due to age

\section{Media}

The media also played a role in how participants styled and viewed their hair growing up.

Participants explained how YouTube helped them learn and develop styling and hair care 
techniques. One participant explained "I think having the YouTube helped. In terms of being like 'okay I can do this myself' ”.

One participant even said that her desire to have straight hair stemmed in part from the media,

I always said ...I don't know when I started wishing I had straight hair, but you know when you realize that you look like something. Yeah I always wanted straight hair, I always wanted it to be like in this styles that I saw that my friends have or like people on T.V. or magazines or whatever. I really wanted like [a] high straight ponytail but it was just impossible so whatever, it's my hair

A second participant expressed a similar experience as she said "I think it's just based on influences, when I started to go to like middle school, high school it was more, like media influences as well”.

\section{Peers}

Peers were a large source of influence in the participant's lives as they shaped the way participants viewed their hair. One participant was fortunate to enough to have peers in their environment that appreciated her natural hair. More specifically, when I asked her how the people around her (i.e.: friends and peers) felt about her transition to her natural hair she said "Yeah...they were more excited for me, and encouraging. I would say definitely".

Interestingly, one of the participants explained a rather negative experience she lived through when attending a predominantly Black school,

Umm it was interesting when I went to the school where everyone else was Black and saw all the different styles of what people used to do. Umm but I feel like I also got some sort of like, like you know how people are talking about, like how you get negative messages by being surrounded by white people about Black hair or whatever

Researcher: Mhmm

And like you [to] an extent you might, I didn't really have that experience, maybe people uncomfortably being like "oh it's so foreign" or like "why does it do that"

Researcher: Yeah 
But I feel like I got a lot of hair hatred at my school where everyone was Black, like that's where the notion of having better hair than someone else's cause like less curly

Researcher: Ohh, ok

And kind of being more frustrated by the hair if that makes any sense

Researcher: Yeahh

Like it's normal to suffer for your hair and like people would do really tight styles and if someone is complaining cause their hair, cause someone braided their hair too tight. And everyone would just be like "oh toughen up"!

She also added,

Oh, no definitely the worst, but now that I'm not in the environment I'm like "my hair is fine!" But back then it was like other people who are more mixed, like had better hair and I feel like the constant focus on the hair was a big thing there cause white people don't understand your hair, they also don't notice it when its better or worse. But then Black people will be like oh you didn't brush your hair properly in the morning and I'm like "Leave me alone, I'm just tired"!

A second woman also expressed and shared how much her peers influenced her hair choices,

but like I feel like when I was in elementary school, it was, Iike I remember it was the way people treated me or talking about my hair, complementing me or whatever like I would internalize it like that's why, not that's why I had to do it, but that was the reasons why but I was like "oh I have to do my hair like that, it looks better like that"

She also shared that others reacted differently when her hair was straightened compared to when it was natural,

The first time I got my hair done was when my perception of my hair changed, because it wasn't until people noticed it that I was like oh ok like no one cared about my other hair now that it's straight, I'm pretty sure that was for grade 6 graduation, I was pretty young like 10-12. So, I got it done and noticed a difference in how people reacted to my hair.

She further added that "Literally people would say oh you should wear like this more often" and stated, 
Participant: Like it was really bad people would be like omg is that your hair, like...just to a point where it's like well what did I walk around looking like before

Researcher: Yeahh, yeah. I get,

Participant: So, I feel like that's what made me so self-conscious, it wasn't like "oh it looks really nice", like moving on. This happens in my professional environment where it's not like a whole ordeal where they're like how...

Researcher: And even if it wasn't why does it matter

Participant: Like is it yours to ask!? I just don't understand

\section{Chapter 5. Discussion}

The current study adds to the literature on girls growing up with Black hair in a Canadian context using a critical paradigm and a Black feminist approach. The study aimed to understand how the experiences of Black Canadian women growing up with Black Hair impacts their identity. Following face-to-face open ended interviews, themes were generated from the data analysis.

\section{Caring for Black Hair}

As explained in the literature review, caring for Black hair can be challenging due to its coiled and coarse texture (Robinson, 2011). Based on the results of the study, it is evident that mothers take a large role in caring for and styling their daughter's hair throughout childhood. More specifically they cared for their daughters' hair based on their own knowledge, time and used products that are more readily accessible to them. As explained in the literature review, the Canadian market has limited hair products for Black hair (Thompson, 2008). Although the market for Black hair supplies is growing, the women explained that as children they did not have many options. More specifically, they used hair products which were not always appropriate for Black hair rendering hair care more difficult and at times painful. As explained 
by Lewis (1999), it is not uncommon for Black females to experience pain while getting their hair styled by their mothers. Indeed, most participants described their hair care experiences with their mothers as painful. Some women explained that this may have been because their mothers were not equipped with the knowledge, products and/or tools to care for their daughters hair, thus, rendering hair care more painful. Moreover, the women also shared that their mothers chemically permed their own hair. Lastly, one participants' mother was obliged to care for her daughters hair along with her own hair meaning that time was limited. Consequently, the hair care process was rushed and painful. Therefore, their own hairstyling may have been easier as relaxed hair is typically thinner and easier to style. Throughout the interviews, I concluded that the Black women experienced some difficulties caring for their hair as children. Overall, the women associated hair care as a child with pain. When considering that Western society favors straight hair, it is not surprising that Black mothers may not always be equipped to style natural hair with the proper tools, products and knowledge.

Another important part of hair care is the hair salon. Visiting hair salons is a common experience for the general population. However, for Black females this experience appears to be of high importance. The women in the study, explained the importance for the hair salons by sharing fond memories and strong ties to the salon and stylists. One woman specifically explained that she does not stray away from her hair stylist as they've developed a connection as she knows exactly how to treat her hair without causing her any pain. Linnan and Ferguson (2007) nicely summarize the bond between Black women and the hair salon by stating "Women know that the bond between a cosmetologist and her customer is a unique blend of loyalty, trust, support and comfort" (p.3). 
As demonstrated throughout the interviews, Black hair styling can be quite a complex and lengthy process. Thus, Black females seem to favor getting their hair styled by professionals For the Black community, the hair salon allows for a private grooming experience in a public context (Gill, 2015). As further stated by Gill (2015) this experience is typically shared with a multitude of other people who may not know each other, but often find common interests and ground for discussion. This resonates with the experience of one participant who mentioned that although she did not understand the language spoken by the people in the salon, the experience was lively.

As mentioned in the literature, many Black females engage in hair altering mainly to achieve the look of straight hair. According to the European standard of beauty, straight hair is more beautiful and acceptable. Indeed, straight hair is more difficult to achieve and maintain for Black females. In fact, this was shared by the women in the study who explained the lengths they went to achieve straight hair. It also became evident that having straight hair was better as it makes life easier, more specifically, it takes less time to style and looks more presentable. These are values and beliefs that were likely transmitted through slavery and colonialism.

Although straightened hair was deemed very important, it would be ignorant to ignore the consequences caused by constant hair altering. When considering that these women still straightened their hair knowing the severe damage it caused to their hair, it becomes apparent how powerful the Western standard of beauty remains as it portrays how they have unknowingly internalized racist beliefs.

\section{Hair Altering}

As described in the literature review, it is not uncommon for Black females growing up in a Western environment to alter their natural hair with chemical perms and hair straightening 
(Thompson, 2018). Indeed, the women in the current study shared that at a young age, they would straighten their hair at the salon for special occasions when they needed to look more presentable. Thus, straight hair was viewed as more presentable and, therefore, better. As they got older, the women continued to straighten their hair with hair thermal straightener's or chemical relaxers. In fact, from a young age, they even begged their mothers to chemically straighten their hair. The women shared a few reasons for wanting straight hair; one of the reasons was to meet the perceived expectations of others. More specifically, one participant expressed that her desire for straight hair stemmed from other people complimenting her when her hair was straight rather than natural. This experience supports the findings in the literature which states that Black females chose to alter their hair to conform with the dominant society's beliefs and expectations (Rosette \& Dumas, 2007). The fact that Black women's lives sometimes revolve around their hair, specifically ensuring that their hair remains straight further proves that white supremacy is deeply entrenched.

Naturally, as described in the literature review, there are many consequences to constant hair altering. First, when women feel constantly obliged to straighten their hair, they miss out on certain activities due to the fear of "ruining" their straight hair. One participant even stated that she refrained from physical activities. This is actually not uncommon for Black women. In fact, a study conducted by Versey (2014) found women avoided physical activity due to the fear of sweating out a hairstyle and concerns for the time it takes to wash, dry and style their hair. Essentially, this study shows that, to some Black women, straight hair is so important that it overrides the benefits of physical activity (Versey, 2014).

Constant hair straightening also leads to severe long term damage to the hair (Johnson \& Bankhead, 2013; Thompson, 2008). One participant shared that she saw the damage in her hair, 
was well educated on the consequences of continuous hair straightening, but chose to ignore the consequences. This shows how strong the power of white supremacy and the Western ideology of beauty can be on Black females as they are willing to constantly straighten their hair knowing the long-term damage it will cause. By not wearing one's hair in its natural state a part of their identity is hidden. As stated by Oyedemi (2016), the act of hair altering can viewed as a physically violent process of erasing one's own "natural hair through poisonous and harmful chemical concoctions in order to achieve straight, finer European and Asian looking hair". When Black females chose to adhere to the European standard of beauty by wearing their hair straight rather than natural, the Black population runs the risk of losing a part of its history and culture.

\section{The Future of Black Hair}

The future of Black hair was a large topic of discussion and interest throughout this study. In the past, Black hair products were a lot more limited. In fact, the lack of Black hair products on the market appeared to be a systemic issues as these hair products were often not found in local beauty shops or drug stores like hair products for the dominant population. This further reinforces the idea that Black hair is viewed as less important. Lack of hair products is essentially another subtle way in which Black females have been made invisible in Western society.

However, the market on products for Black hair is now expanding by becoming more affordable and accessible to Canadians. In the recent years, Black hair products have presented themselves in popular Canadian stores such as Shoppers Drug Mart and Wal-Mart. Previously, these stores only held products for the dominant group and thus, Black females were sometimes obligated to purchase and use products that were not appropriate for their hair. In other instances, Black hair products are displayed in a separate sections. In my personal experience, I’ve noticed 
Black hair products in a separate isle under "Ethnic Care" which further alienates and other Black women as it portrays them as "different" than the dominant group. Luckily, the participants seem hopeful that the integration of Black care products in local popular stores will help Black girls and their caregivers in the coming generations better care for their natural hair.

As the natural hair movement is evolving, Black females who participated in this study are becoming more educated on how to style their hair with the help of the media, specifically YouTube. Two of the women have even "gone natural". As explained by Thomas (2008) many Black females are going back to their natural hair to engage in a healthier lifestyle. Thomas (2008) also adds that Black women who chose to go natural also do so to support their daughters' hair. Interestingly, the women in the study expressed that overtime, with practice and research, they have developed routines to properly care for their hair which they also believe this knowledge will help them care for their future daughters and nieces. It appears that for the Black women in this study, it is important to know how to care for one's hair no matter how they chose to style it. It also seems that different hair techniques may be practiced in the future as the women who participated in the study plan on learning from the challenges they encountered during their childhood.

\section{Influences on Black Hair Styling}

As stated in a section above, mothers played a large role in caring for their Black daughters' hair. However, mothers also provided strong opinions and inputs on how their daughters should style their hair. It is clear that throughout childhood, the mothers of the women in this study were in control of their hair. Only later on when the participants were older and approaching adolescents could they chose how they wanted to style for their hair. Presently, to the best of my knowledge, there are no studies in the literature related to this finding. 
Indeed, all Black females in the current study opted to style their hair straight with the use of chemical relaxers or heat straighteners. The literature demonstrates the number of Black females portrayed with natural hair in the mass media is limited (Lindsey, 2013). Moreover, some of the most influential Black women wear their hair straight, notably Beyoncé. This was also the case when the women in the study were growing up. Representation matters, therefore it is not surprising that these women wanted straight hair like the influencers in the mainstream media. However, it is important to note that YouTube, a popular media platform, has become a source of knowledge on Black hair. A multitude of Black females are using their platforms to showcase the beauty of natural hair and to provide detailed tutorials on how to style and care for natural hair. Some popular influencers include MahagonyCurls (https://www.youtube.com/user/MahoganyCurls/featured, https://www.instagram.com/mahoganycurls/?hl=en), My Natural Sistas (https://www.youtube.com/user/MyNaturalSistas/videos, https://www.instagram.com/mynaturalsistas/?hl=en) and Naptural85 (https://www.youtube.com/user/Naptural85, https://www.instagram.com/naptural85/?hl=en) . In the recent years, the digital media has played a large role in education Black women embarking on a "natural hair journey" (Gill, 2015).

Peers were also a large influence in the lives of the Black females in the current study. According to the Western ideology of beauty, straight hair is more beautiful and acceptable than Black hair. Therefore, it is not surprising that a Black female would receive more compliments when wearing her hair straight. Nevertheless, it can have serious consequences on a Black females' identity as they may potentially internalize these messages and believe their natural hair is not of value, thus reinforcing internalized racism. This experience, although negative, is very 
insightful as it provides a new perspective on how Black women are oppressed. Naturally, a white woman with straight hair is not likely to experience this type of oppression.

Another interesting finding is the discourse on Black hair within the Black community. Due to colonization and slavery, strong divides continue to exist amongst Black populations. Historically, Blacks who have features resembling European characteristics are deemed superior (Oyedemi, 2016). In fact, the comb test was once common to test one's proximity to whiteness (Hunter, 1998). This practice involved passing a comb through one's hair to determine if it was straight enough to pass through it. Even in the recent years, many Black women believe that the distinction between "bad and "good" hair is dependent on "the perceived ease of maintenance of the hair" (Thomas, 2013, p.5). In other words, Thomas (2013) states that when a women's hair is less kinky it is perceived to be easier to comb and therefore is "good" hair. Naturally this means that hair that is less kinky is viewed as more beautiful. In fact, this ideology reinforces the divide within the Black community and supports the beliefs behind white supremacy and demonstrates the consequences of slavery. Therefore, as a result of internalized racism, Black females face judgement for having hair that does not meet the European standard of beauty, they also run the risk of facing judgement from their own communities. One participant even expressed that she felt more hatred for her hair when surrounded by other Black people. The internalized messaged of self-hatred for one's Black features, notably, hair, have been so deeply entrenched that they were passed down to generations of Black females.

\section{Chapter 6. Strengths and Limitations}

\section{Trustworthiness}

Too often, qualitative research is measured against criteria that is most appropriate for quantitative research (Krefting, 1991). Due to the nature of this qualitative study, appropriate 
models need to be utilized. For this MRP, Guba's (1981) model will be used. The model describes distinct strategies for assessing the criteria of qualitative study, (Krefting, 1991). Guba proposes four criteria to evaluate the validity and reliability of a qualitative study, namely, credibility, transferability, dependability and confirmability.

\section{Credibility}

In qualitative research, creditability is "obtained from the discovery of human experiences as they are lived and perceived by informants" (Krefting, 1991, p. 215). As proposed by Sandelowski, a qualitative study is deemed credible when it illustrates an accurate interpretation of the social phenomena in question which allows people who share that experience to immediately understand and recognize the interpretation (as cited by Krefting, 1991). One of the strategies used to increase credibility was to allow participants to read over the transcriptions of their interviews and make any changes they deemed necessary. The participants could request a copy of their transcription on the informed consent form they signed prior to the interview. One participant requested to make edits to her transcription. Lastly, my MRP supervisor, who has extensive research experience, reviewed my work.

\section{Transferability}

Although the goal of this MRP was to hear the voices of Black women who grew up with Black hair in a Canadian context, it is very important to note that the results of this study are not representative of all Black women with Black hair in a Canadian context. As explained by Krefting (1991), applicability, also referred to as "the ability to generalize from the findings to larger populations" (p.216) is not as relevant to qualitative research because its purpose is to describe a specific experience and not generalizabilty. However, steps were taken to increase 
transferability. Prior to showcasing the findings of the research, detailed information regarding the participants, setting and data collection was provided.

\section{Dependability}

As explained by Krefting (1991), variability in qualitative research is expected and consistency is defined in terms of dependability. As previously mentioned, all interviews were audio-recorded and then transcribed. I was sure to listen to the audio-recordings more than once and read the transcriptions multiple times. Participants also had the option to review the transcriptions to ensure their stories were properly portrayed. Moreover, as a way to increase dependability, I engaged in a code-recode process. More specifically, after the initial coding of the data, I waited a few days and recoded the same data to see if I gained any new insights by stepping away from the data. This allowed me to view patterns and details from the interviews that I had previously missed. The first time I coded the data, I didn't include as many quotes from the participants. However, upon further reflection I decided to include more direct quotes as Black women are so often silenced by the dominant population, I determined it important for the readers hear their voices and stories.

\section{Confirmability}

As described in Guba's (1981) model, the neutrality of the data in a qualitative study should be considered rather than the neutrality between the participant and the researcher. Although it is important to establish a relationship with the participants, the researcher must not lose the ability to interpret any findings. Therefore, it is important to engage in reflexivity. In the beginning of this paper, I disclosed that I am a Black woman who grew up in Canada with Black hair. I also acknowledged how my social position as a research may influence data collection and interpretation. Although it is difficult to remain objective in a qualitative research study, I 
ensured to remain as objective as possible by including direct quotes from the participants to support my findings and to allow the voices of the participants to shine through the research.

It is important to note however, that my personal biases may still be reflected in the data analysis. Nevertheless, my position as a Black woman with Black hair brings me at an advantage point in this study. As an "insider" in the study, I was able to relate to several stories the participants shared with me, specifically, the women sometimes used 'we" pronouns rather than "I" which strengthened our researcher-participant relationship and allowed me to better understand their experiences and, therefore, better analyze the data. Indeed, this is something an "outsider" would not be able to accomplish.

\section{Limitations}

Due to time constraints and the nature of this MRP, I was only able to interview 3 Black women who could travel to Toronto. Due to this criterion, only women who were from the GTA participating in the study. If more Black women from various ages and multiple areas of Canada had been interviewed, the data may have presented itself differently. Moreover, more themes may have come from the data analysis.

Additionally, some participants had difficulties recalling their experiences from ages 512. Indeed, there is a possibility that some elements of the stories were inexact. Conversely, it is not uncommon for participants to forget details from a specific event and combine similar experiences into one single generalized memory (Bradburn, Rips \& Shevell, 1987). Therefore, most interviews focused on the participant's experience with their hair at an older age. Although many of the stories stemmed for the participants adolescence and adulthood, it still allowed me to gain insight on the experiences of women growing up with Black hair, and also, an unanticipated outcome, which is how the future of Black hair may look like. Therefore, although 
my intent was to focus on the participants' experiences throughout their childhood, I did not want to take too much control over the participants' story, as one of the main goals of this study is to hear the voices of Black women. This did allow for new perspectives to emerge as the participants shared how much they've learned about their hair during the natural hair movement and subsequently explained how they would care for the hair of future children. Further, the women also predicted the future of Black hair

Lastly, as technology can be unpredictable, I came across technical trouble during one of the transcriptions. More specifically, prior to transcribing an audio-recording, the file became corrupt and the recording was lost. Several attempts were made to reconcile the file but I eventually decided to contact the participant who gladly agreed to do a second interview.

\section{Chapter 7. Implications for ECE practice}

As argued from the outset of this paper, it is crucial for early childhood educators who work with Black girls to understand the historical and cultural importance of hair and how it influences their identity. This research and similar studies done in a Canadian context may potentially allow for the creation and implementation of new practices and frameworks in early childhood educational settings. It is important for early childhood settings to be inclusive, it would be beneficial for these spaces to have more non-tokenistic inclusive materials such as books. There are a list of appropriate books on the market such as Happy to be Nappy by bell hooks and I Love my Hair by Natasha Anastasia Tarpley. Popular video clips such as I love my Hair from Sesame Street and Hair Love created by Matthew A. Cherry promote the love of Black hair and allows for Black hair representation. These resources are important not only to Black girls but to all children. These positive images reduce negative stereotypes against Black girls and Black hair and expose children to diversity. As the Canadian population is becoming 
increasingly diverse it is crucial for educational policies to reflect these changes. It is very beneficial for Black girls to develop a positive relationship with their hair.

The study will also potentially open discussion on the topic of Black hair as it simply adds more knowledge and insights to the literature. ECE's and more specifically, non-Black ECE's, will have more opportunities to read the raw stories of Black women who are often not portrayed in the literature. These stories have the potential to help white ECE's be mindful of their own biases towards Black girls and their hair. Although non racialized ECE's may still feel uncomfortable discussing Black hair, at the least the knowledge and resources are shared. Moreover, a participant mentioned that popular culture plays a role in cultural appropriation. However, it also allows for the general population to become familiar with styles and terminology that are traditionally reserved for Black hairstyles. Therefore, this study introduces these terminologies and styles along with their historical significance and importance which will help ECE's better understand the consequences and the feelings of discomfort surrounded by certain activities that involve "playing with hair". However, it is important to note that these implications are dependent on where this MRP is disseminated. In the future, a version of this MRP may be disseminated in a journal for ECE practitioners such as ECElink along with more traditional scholarly journals.

\section{Chapter 8. Future Study}

The current study explored the voices of Black women who shared their childhood experiences with Back hair. However, in the future, it would be interesting to hear the voices of Black girls as their voices are seldom included in the literature. It would be interesting to view how their hair impacts their identity as they are essentially growing up in the natural hair movement, which brought on changes in the Black community in regards to Black hair care 
(Thomas, 2013). Considering the large influence of the mass media and the impact of the digital market, it would potentially be beneficial to better understand its influence of Black girls and youth.

All participants mentioned the influence their mothers had on their hair growing up, therefore, it would also be interesting to interview Black mothers or guardians of Black girls with Black hair. Black women's voices are not often included in the dominant discourses of society or academia therefore it would be beneficial to hear their perspectives and reasoning behind how they style their daughter's hair. Indeed, this would also bring up other questions and studies. As explained in the literature, not all mothers and caregivers are equipped to care for Black hair. In particular, White caregiver (or non-Black caregivers) do not have the knowledge or experiences to care for Black hair. It would be interesting to have these experiences and stories added to the literature.

Lastly, a topic worth exploring would be the experience of Black boys and youth and Black hair. Thomas (2008) touches upon this topic in her article as she explains that Black males are not exempt from the dominant discourse on Black hair. Some men even chemically alter their hair to achieve styles such as the S-curl which are "easier" to maintain as the texture is typically softer (Thomas, 2008). In 2012, the New York Times included a powerful picture in their paper. The image depicted a young black boy touching president Obama's hair. The photograph occurred after a conversation which consisted of the young boy asking the president if his hair was like his (Calmes, 2012). To everyone's surprise, the president suggested that the young boy touches his hair. This powerful interaction demonstrates that representation does matter. Thus, understand the relationship Black boys have with their natural hair may be very beneficial. 


\section{Chapter 9. Conclusions}

This MRP adds to the current literature by the including the voices of Black females and showcasing their experiences growing up with Black hair in Canadian context. As Canada is becoming increasingly diverse, it is more important than ever for educators to have the knowledge and resources to support children of all backgrounds. As per the findings of this study, Black females are told by several sources how they should style their hair. Most often, Black females end up altering their hair, however, this does not come without any consequences.

This study gives a platform for Black females to share their stories and experiences growing up with Black hair. It is important for these stories to be shared in the literature as these experiences are distinct from the experiences of other women, for example white women who are most often represented in the feminist literature and movements. It is important for Black females with Black hair to be represented in the dominant discourse as a way to help them understand that their natural hair is valued. In turn, these women will be in a better position to encourage the next generation of Black girls to embrace their natural hair. Black girls need to understand that their hair is important and beautiful. Like the women in the study, I am also hopeful that Black females with Black hair will have more positive experiences in the present and future. As more Black women are using their platform to talk about Black hair and educate other Black females (and potentially the general public), I am hopeful that the next generation of Black females will understand how to both care for and embrace their natural hair. 


\section{Appendix A}

\section{Buerson}

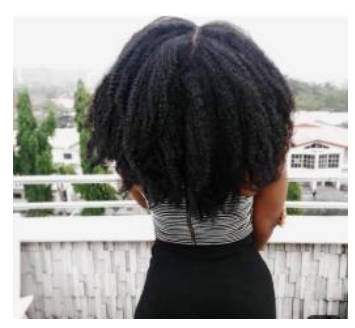

\section{GROWING UP IN CANADA WITH BLACK HAIR - SHARE YOUR STORY RESEARCH PARTICIPANTS NEEDED}

\section{Are you:}

A female identifying Black woman between the ages of 20 and 35 that grew up in Canada between ages 5 to 12 ? Do you identify has having Black Hair? For this study, Black hair is referred as kinky, coiled textured hair.

If you answered yes to the two questions above, please volunteer to participate in the present study. The present study aims to examine how Black Canadian women between the ages of 20 and

35 recall their experiences growing up with Black hair and how it has impacted their identity growing up in a Canadian society. The researcher is seeking to interview 3-5 participants. Individuals who do not identify as female Black women with Black hair and that are under 20 years of age or over 35 will not be accepted as participants.

You will be required to travel to Ryerson University in Toronto on one occasion for a 45 to 60 interview in the month of July or August 2019 to participate in the study, which will be audiorecorded. You will be asked to fill out a demographic questionnaire prior to the start of the interview. Following the questionnaire, you will be asked to recall your experiences with Black hair growing up in Canada between the ages of 5 to 12. Once the interview process is complete, you will receive a $\$ 10$ Starbucks gift card and reimbursement for your travel as long as you provide your receipt (i.e.: bus ticket, presto reload receipt, parking ticket). The gift card and reimbursement will still be given to participants who chose to withdraw from the study before the end. The reimbursement and incentives are funded by the Master of Arts of Early Childhood Studies program.

This study has been reviewed and approved by the Ryerson REB.

If you are interested in participating in the study or require more information please contact: Melissa Bagirakandi, graduate student in the MA Early Childhood Studies Program, Ryerson University at. melissa.bagirakandi@ryerson.ca 


\section{Appendix B}

\section{Ryerson}

Ryerson
University

REB 2019-231

Hello,

My name is Melissa Bagirakandi and I am a graduate student at Ryerson University in the School of Early Childhood Studies.

This research study I am conducting is being done in partial completion of my Master of Arts degree in early childhood studies and my supervisor's name is Dr. Rachel Berman. The focus of the research is to examine how Black Canadian women between the ages of 20 and 35 recall their experiences growing up with Black hair and how it has impacted their identity growing up in Canadian society. I am seeking to interview 3-5 participants. The goal is to further understand how Black hair in a Canadian context shapes the identity of young Black girls.

To participate in the study, you must be a female identifying Black woman between the ages of 20 to 35 who grew up in Canada between ages 5 to 12 . You must also identify as having Black hair. Individuals who do not identify as Black women with Black hair and that are under 20 years of age or over 35 will not be accepted as participants. Throughout the study, Black hair is referred as kinky, coiled textured hair.

If you agree to volunteer, you will be asked to travel to Ryerson University in Toronto on one occasion in July or August 2019 for 45 to 60 minutes interview. You will be asked to fill out a demographic questionnaire. Following the questionnaire, you will be asked to recall your experiences with Black hair growing up in Canada between the ages of 5 to 12 . You will receive a $\$ 10$ gift card to Starbucks at the end of the interview. You will also be reimbursed for your travel as long as you provide your receipt (i.e.: bus ticket, presto reload receipt or parking ticket). If you chose to withdraw from the study, you will still receive this gift card and reimbursement for your travel. The reimbursement and incentives are funded by the Master of Arts of Early Childhood Study program. Prior to your participation in the study, the researcher will ask you if your interview can be audio-recorded. If you do not wish to be audio-recorded, you will not be able to participate in the study. In the event, a potential participant has a previous relationship with the researcher, it will be emphasized that participation is voluntary, and this will not impact 
any future relationships with the researcher or the supervisor Dr. Rachel Berman nor will it impact any future relationships with Ryerson University.

This study has been reviewed and approved by the Ryerson Research Ethics Board.

If you are interested in participating in this research study please contact:

Melissa Bagirakandi, melissa.bagirakandi@ ryerson.ca 
Appendix C

\author{
Ryerson \\ University \\ Ryerson University \\ Consent Agreement \\ REB 2019-231
}

You are being invited to participate in a research study. Please read this consent form in order to understand what your participation will involve. Before you consent to participate, please ask any questions to be sure you understand what your participation will involve.

Title of the Study: Sharing my story of growing up with black hair in Canada

Investigator: This research study is being conducted by Melissa Bagirakandi, B.A. and is being supervised by Dr. Rachel Berman from the Graduate Program in the School of Early Childhood Studies at Ryerson University.

If you have questions or concerns about the research, please feel free to contact Melissa Bagirakandi, melissa.bagirakandi@ryerson.ca or Rachel Berman, rcberman@ryerson.ca

Purpose of the research: This study is designed to fill the gap in the literature on hair and identity as it pertains to the voices and experiences of Black young girls. In fact, in literature on Black hair and identity, Black young girls are often excluded. The goal of this study is to hear the voices of Black women as it pertains to their childhood, growing up with Black hair. To participate in the study, you must be a female identifying Black women between the ages of 20 to 35 who grew up in Canada between ages 5 to 12 . You must also identify as having Black hair. Individuals who do not identify as Black women with Black hair and that are under 20 years of age or over 35 will not be accepted as participants. You will also be required to travel to Ryerson University on one occasion during the month of July or August 2019. Throughout the study, Black hair is referred as kinky, coiled textured hair. For this study, 3 to 5 Black women between the ages of 20 to 35 who have grown up in Canada between ages 5 to 12 will be interviewed. The research is being conducted by a graduate student in partial completion of a Master of Arts 
degree in early childhood studies. The results will contribute to the students' Master's Research Project (MRP).

What you will be asked to do in the research: If you volunteer to participate in this study you will be asked to do the following things:

1)You will be required to travel to Ryerson University in Toronto to participate in the study during the month of July or August 2019.

2) You will be asked to share your story growing up in Canada between the ages of 5 to 12 in an interview, which will last approximately 45 to 60 mins. A few potential questions will include: I am able to care for my hair as well as most other people and I feel that my hair is of value, at least on an equal plane with others.

3) Prior to the interview, you will be asked to answer a short demographic form.

4)At the end of this consent form you will be asked for your consent to audio-record your interview. In the event you do not want to be audio-recorded, you will not be able to participate in this study.

Potential Benefits: This research creates a space for Black women to share their experiences growing up with Black hair. I cannot guarantee however, that you will receive any benefits from participating in the study.

What are the Potential Risks to you as a Participant: The risks for the participants are low/minimal. You may feel uncomfortable, anxious or sad when recalling their experiences growing up in Canada with Black hair. If you do feel uncomfortable or anxious, please remember that you are not obliged to answer all questions, you may skip a question and/or you can withdraw from the study at any time without any consequences. Through the sharing of your personal stories, there may be the possibility of personal identity being revealed. However, you will have the opportunity to create your own pseudonym and make any edits to the researcher's transcription of your audio-recorded interview. Resources to discuss any distress that you may feel will be provided at the conclusion of the interview.

Confidentiality: Your information will be held confidential throughout the recruitment process, the data collection and analysis. Appropriate safeguards will be in place to protect the privacy of all participants in the study from unauthorized access, use, disclosure, modification, loss and theft. During transcription, pseudonyms will be used to keep your identity as confidential as possible. If you wish, you can even create your own pseudonym. You will also have the right to review and edit the transcription of the audio recordings of your interview. This will be shared with you through a secure and encrypted shared Ryerson google document once the transcription is complete. Following the transcription of your interview, you will have two (2) weeks to email your feedback and edits of your transcriptions. In the event you do not indicate you would like a transcript of the interview for review and to provide feedback on the consent form, you will still 
have the opportunity to request a review of their transcript. However, you will still have two (2) weeks from the time the transcription is complete to make and send back any edits. The data will only be shared between the principal investigator and the supervisor using the shared Ryerson Google drive which is secure and encrypted. Any hard copies of the data e.g.: consent forms and transcriptions will be filed in a locked cabinet in the supervisor's office in the School of Early Childhood Studies at Ryerson University. Consent forms and all other hard-copy data will be stored separately. The data will be kept for a year; in September 2020, all consent forms and transcriptions will be shredded. The audio-recordings will be deleted as soon as the transcriptions are complete. The research may be shared in research conferences or journal publications however pseudonyms will be used to protect your identity. At the end of the interviews, the researcher will ask you if you wish to receive a copy of the final research project. In the event you wish to receive the final project, you will be asked to provide the researcher with your email address and a copy of the research study will be emailed to you. You can also have access to Ryerson's digital repository where you will also be able to view the research study by following this link: https://digital.library.ryerson.ca/islandora/search/\%2A\%3A\%2A?islandora_solr_search_navigati on $=0 \& \mathrm{f} \% 5 \mathrm{~B} 0 \% 5 \mathrm{D}=$ mods_extension_degree_department_ms $\% 3 \mathrm{~A} \% 22$ Early $\% 20$ Childhood $\% 20$ Studies \%22

Incentives for participation: You will not be paid to participate in this study. However, you will receive a $\$ 10$ gift card to Starbucks at the end of the interview even if you chose to withdraw from the study before the end. The incentives for the study are funded by the Master of Arts Early Childhood Studies program.

Cost of participation: You will need to travel to Ryerson University in Toronto, Ontario. Therefore, the cost associated with the study may be public transportation or parking at Ryerson University. However, the researcher will provide reimbursement for travel as long as you are able to provide a receipt (i.e.: bus ticket, receipt from reloading your presto card, parking ticket). You will receive reimbursement even if you chose to withdraw from the study before the end. The reimbursements for the study are funded by the Master of Arts Early Childhood Studies program.

Voluntary participation and withdrawals: Participation in this study is completely voluntary. You can choose whether to be in this study or not. If any question makes you uncomfortable, you can skip that question. You may stop participating at any time and you will still be given the incentives described above. If you choose to stop participating, you may also choose to not have your data included in the study. Your choice of whether or not to participate will not influence your future relations with Ryerson University or the investigator, Melissa Bagirakandi, B.A. or her supervisor Dr. Rachel Berman. 
Questions about the study: If you have any questions about the research now, please ask. If you have questions later about the research, you may contact:

Melissa Bagirakandi

melissa.bagirakandi@ryerson.ca

Rachel Berman

rcberman@ryerson.ca

This study has been reviewed by the Ryerson University Research Ethics Board. If you have questions regarding your rights as a participant in this study, please contact:

Research Ethics Board

c/o Office of the Vice President, Research and Innovation

Ryerson University

350 Victoria Street

Toronto, ON M5B 2K3

416-979-5042

rebchair@ryerson.ca

\section{CONFIRMATION OF THE AGREEMENT}

Your signature below indicates that you have read the information in this agreement and have had a chance to ask any questions you have about the study. Your signature also indicates that you agree to participate in the study and have been told that you can change your mind and withdraw your consent to participate at any time. You have been given a copy of this agreement. You have been told that by signing this consent agreement you are not giving up any of your legal rights.

Name of participant (Please print)

Signature of participant

Date 
I agree to be audio-recorded for the purposes of this study. I understand how these recordings will be stored and destroyed.

Signature of participant

Date

Please indicate if you would like a copy of the interview transcript to review and provide your feedback to the researcher.

$\square$ Please check the box if you would like to have a summary of the final report emailed to you

Email address: 


\section{Appendix D}

\section{Demographic Questionnaire}

1) Age:

2) Name the country where you were born:

3) Name the Canadian province where you spend most of your childhood?:

i) Which region or city did you spend most of your childhood: 


\section{Appendix E}

\section{$\begin{array}{ll}\text { Research } \\ \text { Ryerson } & \text { Ethics Board }\end{array}$}

To: Melissa Bagirakandi

Early Childhood Studies

Re: REB 2019-231: Share my story growing up with Black hair

Date: July 16, 2019

Dear Melissa Bagirakandi,

The review of your protocol REB File REB 2019-231 is now complete. The project has been approved for a one year period. Please note that before proceeding with your project, compliance with other required University approvals/certifications, institutional requirements, or governmental authorizations may be required.

This approval may be extended after one year upon request. Please be advised that if the project is not renewed, approval will expire and no more research involving humans may take place. If this is a funded project, access to research funds may also be affected.

Please note that REB approval policies require that you adhere strictly to the protocol as last reviewed by the REB and that any modifications must be approved by the Board before they can be implemented. Adverse or unexpected events must be reported to the REB as soon as possible with an indication from the Principal Investigator as to how, in the view of the Principal Investigator, these events affect the continuation of the protocol.

Finally, if research subjects are in the care of a health facility, at a school, or other institution or community organization, it is the responsibility of the Principal Investigator to ensure that the ethical guidelines and approvals of those facilities or institutions are obtained and filed with the REB prior to the initiation of any research.

Please quote your REB file number (REB 2019-231) on future correspondence.

Congratulations and best of luck in conducting your research.

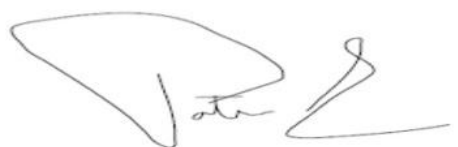

Dr. Patrizia Albanese, $\mathrm{PhD}$

Chair, Ryerson University Research Ethics Board

The Following protocol attachments have been reviewed and approved. 


\section{References}

Alsaawi, A. (2014). A critical review of qualitative interviews. European Journal of Business and Social Sciences, 3(4) 149-156.

Ashley, W., \& Brown, J. C. (2015). Attachment tHAIRapy: A culturally relevant treatment paradigm for African American foster youth. Journal of Black Studies, 46(6), 587-604.

Bing, T., LeBoff, J., Platt, M., Lathan, S. (Producers) \& al-Mansor, H. (Director). (2018). Nappily Ever After [Motion picture]. United States: Netflix.

Barnett, M. (2016). The politics of black hair: A focus on natural vs relaxed hair for AfricanCaribbean women. Ideaz, 14, 69-100.

Berman, R., Daniel, B. J., Butler, A., MacNevin, M., \& Royer, N. (2017). Nothing, or almost nothing, to report: Early childhood educators and discursive constructions of colorblindness. International Critical Childhood Policy Studies Journal, 6(1), 52-65.

Berger, R. (2015). Now I see it, now I don't: Researcher's position and reflexivity in qualitative research. Qualitative research, 15(2), 219-234.

Board, R. E (2018). Research Ethics. Retrieved from Ryerson University: h ttps://www.ryerson.ca/research/resources/ethics/human/\#1

Bradburn, N. M., Rips, L. J., \& Shevell, S. K. (1987). Answering autobiographical questions: The impact of memory and inference on surveys. Science, 236(4798), 157-161.

Braun, V., Clarke, V., Hayfield, N., \& Terry, G. (2018). Thematic analysis. Handbook of research methods in health social sciences, 1-18. New York, NY: Springer.

Brisbon, A. (2009b). Good Hair, Bad Hair: African-American Hair Relations in the Early Twentieth Century. Undergraduate Humanities Forum 2008-09: Change. Retrieved from http://repository.upenn.edu/uhf_2009/1 
Brown, A. L., \& Brown, K. D. (2010). Strange fruit indeed: Interrogating contemporary textbook representations of racial violence toward African Americans. Teachers College Record, $112(1), 31-67$

Caldwell, P. M. (1991). A hair piece: Perspectives on the intersection of race and gender. Duke Law Journal, 1991(2), 365-296.

Calmes, J. (2012). When a boy found a familiar feel in a pat of the head of state. The New York Times, 23.

Carby, H. (2007). White woman listen! Black feminism and the boundaries of sisterhood. In CCCS Selected Working Papers (pp. 753-774). New York: Routledge.

Craig, M. L. (2006). Race, beauty, and the tangled knot of a guilty pleasure. Feminist Theory, 7(2), 159-177.

Combahee River Collective (1977) ‘A black feminist statement’ Reprinted in Linda Nicolson (ed.) (1997) The Second Wave: A Reader in Feminist Theory, New York: Routledge.

Collins, P. H. (1990). Black feminist thought in the matrix of domination. Black feminist thought: Knowledge, consciousness, and the politics of empowerment, 138, 221-238.

Collins, P. H. (1986). Learning from the outsider within: The sociological significance of Black feminist thought. Social problems, 33(6), s14-s32.

Creswell, J. W. (2014). Research design: Qualitative, quantitative, and mixed methods approaches (Fourth ed.). Thousand Oaks, CA: Sage Publications

Dash, P. (2006). Black hair culture, politics and change. International Journal of Inclusive Education, 10(1), 27-37. doi:10.1080/13603110500173183 
DeGruy, J. (2005). Post traumatic slave syndrome: America's legacy of enduring injury and healing. Milwaukie, Oregon: Uptone Press

Dei, G. J. S. (2003). Schooling and the dilemma of youth disengagement. McGill Journal of Education/Revue des sciences de l'éducation de McGill, 38(002), page numbers. 241-256.

Dei, G. S. (2008). Race and minority schooling in Canada: Dealing with questions of equity and access in education. In Z. Bekeran \& E. Kopelowitz (Eds.), Cultural education-cultural sustainability: Minority, diaspora, indigenous and ethnoreligious groups in multicultural societies. New York, NY: Routledge.

Dei, G. J. S. (2015). Reflections on "Dropping Out" of school: Meeting the challenge of youth engagement. Education Canada, 55(2), 13-17.

Escayg, K. A., Berman, R., \& Royer, N. (2017). Canadian children and race: Toward an antiracism analysis. Journal of Childhood Studies, 42(2), 10-21.

Fogelman, D. \& Todd, D. (Writers) \& Requa, J. \& Ficarra, G. (Directors). (2016). The Pool [Television series episode]. In D. Fogelman (Producer), This is Us, California: 20th Television.

Fong, E. (1996). A comparative perspective on racial residential segregation: American and Canadian experiences. The Sociological Quarterly, 37(2), 199-226.

Gill, T. M. (2015). \# TeamNatural: Black Hair and the Politics of Community in Digital Media. Journal of Contemporary African Art, 2015(37), 70-79.

Hoffmann, E. A. (2007). Open-ended interviews, power, and emotional labor. Journal of Contemporary Ethnography, 36(3), 318-346.

Hunter, M. L. (1998). Colorstruck: Skin color stratification in the lives of African 
American. Sociological Inquiry, 68(4), 517-535.

Iromuanya, J. (2018). Are We All Feminists? The Global Black Hair Industry and Marketplace in Chimamanda Ngozi Adichie's Americanah. Meridians, 16(1), 163-183.

Johnson, T. A., \& Bankhead, T. (2014). Hair it is: Examining the experiences of Black women with natural hair. Open Journal of Social Sciences, 1(4) 92-101.

Josselson, R. (2007). The ethical attitude in narrative research. In D.J. Clandinin (Ed.), Handbook of narrative inquiry: Mapping a methodology. Thousand Oaks, CA: Sage Publications.

King, L. J., \& Simmons, C. (2018). Narratives of black history in textbooks: Canada and the United States. The Wiley international handbook of history teaching and learning, 93116. New York: John Wiley \& Sons, Inc.

King, V., \& Niabaly, D. (2013). The Politics of Black Women's Hair. Journal of Undergraduate Research at Minnesota State University, Mankato, 13(4), 1-19.

Kivunja, C., \& Kuyini, A. B. (2017). Understanding and Applying Research Paradigms in Educational Contexts. International Journal of Higher Education, 6(5), 26-41.

Krefting, L. (1991). Rigor in qualitative research: The assessment of trustworthiness. American Journal of Occupational Therapy, 45(3), 214-222.

Kurtz-Costes, B., DeFreitas, S. C., Halle, T. G., \& Kinlaw, C. R. (2011). Gender and racial favoritism in Black and White preschool girls. British Journal of Developmental Psychology, 29(2), 270-287.

Leavy, P. (2017). Research Design: Quantitative, Qualitative, Mixed Methods, Arts-Based, and Community Based Participatory Approaches. New York: Guilford Press.

Lester, N. A. (2000). Nappy edges and goldy locks: African-American daughters and the politics 
of hair. The Lion and the Unicorn, 24(2), 201-224.

Lewis, M. L. (1999). Hair Combing Interactions: A New Paradigm for Research With African-American Mothers. American Journal of Orthopsychiatry, 69(4), 504-514.

Lindsey, T. B. (2013). “One time for my girls”: African-American girlhood, empowerment, and popular visual culture. Journal of African American Studies, 17(1), 22-34.

Linnan, L. A., \& Ferguson, Y. O. (2007). Beauty salons: a promising health promotion setting for reaching and promoting health among African American women. Health Education \& Behavior, 34(3), 517-530.

Mercer, K. (1987). Black hair/style politics. New Formations, 1(3). 33-54.

Merriam, S. B., Johnson-Bailey, J., Lee, M.Y., Kee, Y., Ntseane, G., \& Muhamad, M. (2001). Power and positionality: Negotiating insider/outsider status within and across cultures. International Journal of Lifelong Education, 20(5), 405-416.

Merriam, S. B. (2002). Introduction to qualitative research. Qualitative research in practice: Examples for discussion and analysis, 1(1), 1-17.

Neal, J. W., Neal, Z. P., VanDyke, E., \& Kornbluh, M. (2015). Expediting the analysis of qualitative data in evaluation: A procedure for the rapid identification of themes from audio recordings (RITA). American Journal of Evaluation, 36(1), 118-132.

Oyedemi, T. (2016). Beauty as violence: 'beautiful 'hair and the cultural violence of identity erasure. Social Identities, 22(5), 537-553.

Robinson, C. L. (2011). Hair as race: Why "Good hair” may be bad for black females. Howard Journal of Communications, 22(4), 358-376. doi:10.1080/10646175.2011.617212

Rosette, A. S., \& Dumas, T. L. (2007). The hair dilemma: Conform to mainstream expectations 
or emphasize racial identity. Duke Journal of Gender and Law Policy, 14, 407-421.

Scales-Trent, J. (1989). Black women and the constitution: Finding our place, asserting our rights. Harvard Civil Rights-Civil Liberties Law Review, 25, 9-44.

Scotland, J. (2012). Exploring the Philosophical Underpinnings of Research: Relating Ontology and Epistemology to the Methodology and Methods of the Scientific, Interpretive, and Critical Research Paradigms. English language teaching, 5(9), 9-16.

Sesame Street. [Screen name]. (2010, October 12). I Love my Hair [Video file]. Retrieved from: https://www.youtube.com/watch?v=enpFde5rgmw

Stiel, L., Adkins-Jackson, P. B., Clark, P., Mitchell, E., \& Montgomery, S. (2016). A review of hair product use on breast cancer risk in African American women. Cancer medicine, 5(3), 597-604.

Tate, S. (2007). Black beauty: Shade, hair and anti-racist aesthetics. Ethnic and racial studies, 30(2), 300-319.

Davidson, T. (2015). TDSB accused of targeting black students' hair styles. Toronto Sun. Retrieved from: https://torontosun.com/2015/12/04/tdsb-accused-of-targeting-blackstudents-hair-styles/wcm/3d0ac81e-59ee-49b1-b107-3cf5dc29ef74

Thomas, T. (2013). 'Hair' They Are: The Ideologies of Black Hair. The York Review, 9(1), 1-10.

Thompson, C. (2008). Black women and identity: What's hair got to do with it. Michigan Feminist Studies, 22(1), 1-6.

UNESCO. (n.d.). Early childhood care and education. Retrieved from: https://en.unesco.org/themes/early-childhood-care-and-education Versey, H. S. (2014). Centering perspectives on Black women, hair politics, and physical activity. American Journal of Public Health, 104(5), 810-815. 
Watts-Jones, D. (2002). Healing internalized racism: The role of a within-group sanctuary among people of African descent. Family Process, 41(4), 591-601.

White, Shauntae B. (2005). Releasing the Pursuit of Bouncin' and Behavin’ Hair: Natural Hair as an Afrocentric Feminist Aesthetic for Beauty. International Journal of Media and Cultural Politics. 1(3), 296-308.

Womack, S. (2016). I Know I Can't: The Negative Effects of Post Traumatic Slave Syndrome's on the well-being of African American college students. The Vermont Connection, 37(1), 15.

Yerima, D. (2017). Regimentation or Hybridity? Western Beauty Practices by Black Women in Adichie's Americanah. Journal of Black Studies, 48(7), 639-650. 